2019

\title{
Culturing Echinoderm Larvae Through Metamorphosis
}

\author{
Jason Hodin \\ University of Washington \\ Andreas Hayland \\ University of Guelph \\ Annie Mercier \\ Marine Institute, Memorial University \\ Bruno Pernet \\ California State University, Long Beach \\ David L. Cohen \\ Anuenue Fisheries Research Center
}

See next page for additional authors

Follow this and additional works at: https://scholarworks.wm.edu/asbookchapters

Part of the Biology Commons, and the Cell and Developmental Biology Commons

\section{Recommended Citation}

Hodin, J., Hayland, A., Mercier, A., Pernet, B., Cohen, D. L., Hamel, J., Allen, J. D., McAlister, J. S., Byrne, M., \& George, S. B. (2019). Culturing Echinoderm Larvae Through Metamorphosis. Methods in Cell Biology (pp. 125-169). Elsevier. https://scholarworks.wm.edu/asbookchapters/98

This Book Chapter is brought to you for free and open access by the Arts and Sciences at W\&M ScholarWorks. It has been accepted for inclusion in Arts \& Sciences Book Chapters by an authorized administrator of W\&M ScholarWorks. For more information, please contact scholarworks@wm.edu. 


\section{Authors}

Jason Hodin, Andreas Hayland, Annie Mercier, Bruno Pernet, David L. Cohen, Jean-Francois Hamel, Jonathan D. Allen, Justin S. McAlister, Maria Byrne, and Sophie B. George 
running title: Culturing echinoderm larvae

\section{CULTURING ECHINODERM LARVAE THROUGH METAMORPHOSIS}

Jason Hodin ${ }^{1,}$, Andreas Heyland ${ }^{2}$, Annie Mercier ${ }^{3}$, Bruno Pernet ${ }^{4}$, David L. Cohen ${ }^{5}$, Jean-François

6 Hamel $^{6}$, Jonathan D. Allen7, Justin S. McAlister ${ }^{8}$, Maria Byrne ${ }^{9}$, Paula Cisternas ${ }^{9}$ and Sophie B. George $^{10}$

8

${ }^{1}$ Friday Harbor Labs, University of Washington, Friday Harbor WA, USA

10 '2University of Guelph, Guelph ON, Canada

${ }^{3}$ Department of Ocean Sciences, Memorial University, St. John's NL, Canada

$12{ }^{4}$ Department of Biological Sciences, California State University-Long Beach, Long Beach CA, USA ${ }^{5}$ State of Hawai'i, Division of Aquatic Resources, Ānuenue Fisheries Research Center, Honolulu HI,

14 USA

${ }^{6}$ Society for the Exploration and Valuing of the Environment (SEVE), Portugal Cove-St. Philips NL,

16 Canada

${ }^{7}$ Biology Department, College of William and Mary, Williamsburg VA, USA

$18{ }^{8}$ Department of Biology, College of the Holy Cross, Worcester MA, USA

${ }^{9}$ School of Medical Sciences and School of Life and Environmental Sciences, University of Sydney,

20 Sydney NSW, Australia

${ }^{10}$ Department of Biology, Georgia Southern University, Statesboro GA, USA

$22{ }^{*}$ Corresponding author: larvador@uw.edu 


\section{ABSTRACT}

Echinoderms are favored study organisms not only in cell and developmental biology, but also physiology, larval biology, benthic ecology, population biology and paleontology, among other fields. However, many echinoderm embryology labs are not well-equipped to continue to rear the

28 post embryonic stages that result. This is unfortunate, as such labs are thus unable to address many intriguing biological phenomena, related to their own cell and developmental biology studies, that emerge during larval and juvenile stages. To facilitate broader studies of post-embryonic echinoderms, we provide here our collective experience rearing these organisms, with suggestions

32 to try and pitfalls to avoid. Furthermore, we present information on rearing larvae from small laboratory to large aquaculture scales. Finally, we review taxon-specific approaches to larval rearing through metamorphosis in each of the four most commonly-studied echinoderm classes -asteroids, echinoids, holothuroids and ophiuroids.

\section{KEYWORDS}

urchin, sea star, brittle star, sea cucumber, planktotrophy, lecithotrophy, feeding, non-feeding, 40 husbandry, culture 


\section{Why Culture Echinoderm LaRVAe?}

48 Most of the chapters in these volumes are focused on applying cell and molecular biology techniques to echinoderms. In the past, the vast majority of such studies have involved experiments with embryos, due to the ease of obtaining large quantities of synchronously developing, optically clear zygotes from a diversity of species. Nevertheless, when developmental studies of echinoderms

52 cease during late embryonic development, they leave out an enormous amount of interesting biology: the development of diverse functioning organ systems (e.g., digestive, nervous, excretory);

54 the emergence of larval swimming and feeding behaviors, phenotypic plasticity, cloning, and regeneration; extensive changes in development that accompany independent evolutionary losses

56 of larval feeding in diverse lineages; a profound shift in symmetry from bilateral to pentameral; determination of the key life-history transition of where and when to settle at the end of larval

58 development; and the dramatic habitat shift from planktonic life to the sea floor (Chia \& Burke, 1979; Elphick \& Melarange, 2001; Hodin, 2006; Lawrence, 2013; Lyons et al., this volume;

60 Strathmann, 1971, 1979; Su et al., this volume; Wray, 1996; Yaguchi et al., this volume). Indeed, early developmental processes are interesting in part because they affect the morphology of both larvae and adults; as such, studying post-embryonic stages is necessary for a full appreciation of the embryonic processes themselves. Furthermore, as other authors in these volumes have argued, rearing larvae and juveniles is critical to our ability to implement some modern methods in genetics, as well as aquaculture.

Among the features that make echinoderms excellent study organisms are their remarkable 
diversity in adult morphology and life history, in the context of well-resolved evolutionary relationships and a robust fossil record stretching back into the early Cambrian (Smith, 1997 for review). As we describe in the sections below, one can rear large numbers of larvae at low cost through metamorphosis, consistently and in many cases synchronously, by following a few basic

72 procedures. We hope that this chapter will pull back the curtain on echinoderm larval rearing, revealing it as an undertaking that any motivated researcher can master. Our aim is to encourage

74 laboratories to take full advantage of the complex life histories of the organisms that they study to address the widest array of questions relevant to their particular research interests.

There are nearly as many techniques for successfully culturing larvae as there are biologists working with them, and protocols always need to be adapted to suit the available species, space and materials. Indeed we co-authors have gleaned many useful tips from one another while assembling this chapter. Therefore, we will not provide overly specific step-by-step instructions herein, but instead offer our collective experience with guidelines to follow and pitfalls to avoid in the hopes of

82 promoting more widespread studies of the larvae and early juveniles that all too often end up down the embryologist's sink drain.

\section{General Culturing Methods}

We here outline methods that, in our experience, apply to echinoderm larvae in general. We discuss taxon-specific methods in subsequent sections.

90 Top Five Things to keep in mind for larval culturing (in order of ontogeny) 
92 1) Use clean, 'embryo safe' containers and high-quality seawater

94 Larvae need to be cultured in containers, which either:
a) are new;

96

b) have never been used with any detergent, toxic chemicals, heavy metals, etc.; or

c) have been cleaned in such a way as to completely remove any such compounds (see below).

98

We mark such containers clearly to indicate that they are safe for embryos or larvae, and are

100 distinguished from other laboratory containers. Containers can be glass (preferred) or plastic. Note that plastic containers - particularly when new or after repeated use-could leach compounds into 102 cultures that may impact larval development.

104 To clean containers between uses, wash thoroughly with tap water and never use any detergents. A brush or scrubbing pad can be used to remove adherent materials or other debris. Then, rinse with 106 distilled, deionized or reverse-osmosis filtered water (all henceforth referred to here as " $\mathrm{dH}_{2} \mathrm{O}^{\prime \prime}$ ).

108 Note that new glass or plastic containers should be washed in the manner described above before first use: the manufacturing process can leave a residue. We recommend smelling a new container 110 before use; it should be free of any powerful odor. Likewise, some types of laboratory plasticware, when stored, will off-gas plastic compounds. We thus recommend storing containers without lids 112 when possible, and rinsing thoroughly after extended storage. 
114 Glassware that has either been used with potentially harmful compounds (see "b" above) or is of unknown origin can be made safe for use by acid washing with $1 \mathrm{~N} \mathrm{HCl}$ for 10 min, followed by

116 thorough rinsing in tap water, then several rinses in $\mathrm{dH}_{2} \mathrm{O}$. The acid can be saved and used numerous times before being disposed as hazardous waste. Plasticware should never be acid

118 washed since that can compromise the surface of the plastic and thus lead to compounds being increasingly leached into subsequent embryonic and larval cultures.

In wet lab settings with access to flowing seawater (SW), another method for cleaning new or mildly compromised glassware or plasticware is to soak the containers in running SW for 1-2 weeks; a brush may be necessary to remove the biofilm that grows on the inside of the containers.

124 Containers exposed to toxic compounds should not be rinsed in this way to avoid discharging harmful substances into the ocean. If a laboratory plans to expose larval cultures on a regular basis to certain compounds that would otherwise make those containers unsuitable for standard cultures, they can be marked and maintained as such.

We recommend culturing larvae in high-quality natural SW deriving from offshore to minimize effects of pollution and fluctuating salinity from terrestrial sources. Some degree of filtration is needed, in particular to remove potential predators. Minimally, this can involve the use of bag filters or unbleached coffee filters. Filtration through a 5- $\mu \mathrm{m}$ mesh will further remove most phytoplankton cells, which may be preferred for controlling food levels in a consistent manner, and 134 any toxic algae (but not their dissolved products, which may affect embryos or larvae). If the researcher wishes to retain the natural bacterial biota, the $5-\mu \mathrm{m}$ mesh is a good choice. However, 136 many researchers may wish to remove bacteria to reduce the likelihood of bacterial overgrowth in 
closed cultures, in which case we recommend filtration through a 0.45- or 0.2- $\mu$ m mesh filter. See

138 Strathmann (2014) for details.

140 If natural SW is unavailable, commercially available artificial seawater (ASW) yields good results when $\mathrm{dH}_{2} \mathrm{O}$ is used to make up the ASW (see Strathmann, 2014 for protocols). We recommend ASW

142 formulations that include a diversity of trace elements; we have observed that simple ASW recipes such as the Marine Biological Laboratory (MBL) standard ASW (Cavanaugh, 1975) do not support

144 healthy long-term growth in echinoderms. Once the salts have gone into solution, we recommend a $0.2-0.45 \mu \mathrm{m}$ filtration step, followed by salinity adjustment using $\mathrm{dH}_{2} \mathrm{O}$. It is also critical to allow

146 freshly made ASW to off-gas $\mathrm{CO}_{2}$ (achieved by simply leaving it in open or loosely-capped containers) for at least $12 \mathrm{~h}$ before use in cultures.

2) Rear larvae at low density

Although it is tempting to culture larvae at high density (more potential study material in a smaller total volume) we strongly advise against succumbing to this temptation. Many studies have noted that larvae develop faster and more consistently when cultured at lower density (e.g., Suckling,

154 Terry \& Davies, 2018), particularly during late stages. Larvae in high-density, closed system cultures suffer from more rapid accumulation of waste products leading to poor water quality, frequent

156 direct interactions with other larvae, and, for those larvae that require food to complete metamorphosis (i.e., planktotrophic development), less food per larva. Dying larvae in crowded 158 conditions can create a positive feedback loop of larval death. High densities (sometimes extremely high, in excess of 10 larvae per $\mathrm{ml}$ ) are of particular concern in studies where a stressor - such as 
160 high temperature or low pH - is applied. In such cases, the effects of the stressor may not be distinguishable from possible interaction effects with crowding. Natural zooplankton densities in

162 the sea range from $\sim 1$ individual per $10 \mathrm{~L}$ to $\sim 1$ individual per $5 \mathrm{~mL}$ (Kacenas \& Podolsky, 2018; Roman, Holliday \& Sanford, 2001). Although the lowest densities here are impractical for laboratory 164 culture, attempts to at least approach the natural range seem prudent.

166 In species in which pre-hatching stages are negatively buoyant and sink to the bottom, initial culture density should be kept low enough that pre-hatching stages do not form a layer more than one embryo thick, to allow sufficient oxygen diffusion to all embryos and to promote synchronous development. Alternatively, cultures can be gently stirred to keep embryos suspended.

Once embryos have hatched, decant embryos swimming near the surface into a clean container,

172 then stir and collect a few replicated aliquots to estimate the number present. Transfer embryos into natural filtered seawater (FSW) or ASW, aiming for a density of $\leq 1$ embryo per $\mathrm{ml}$ for early

174 stages, once feeding has been initiated (for those larvae requiring food). Lower densities during early larval stages may lead to more rapid and synchronous growth and better survival as larvae 176 feed and begin excreting waste products.

178 At later stages, the density of larvae in culture is ideally 1 larva per $4 \mathrm{ml}$ or lower. Unusually large larvae [e.g., those of diadematoid echinoids with extremely long larval arms (see Fig. 8G below), 180 some ophiuroids, giant seastar larvae in the genus Luidia) should be cultured at lower density still: no more than 1 larva per $10 \mathrm{ml}$. Our anecdotal observations in a diversity of echinoids indicate that 182 rapid reductions in density can induce larval cloning (c.f., McDonald and Vaughn, 2010), which 
makes cultures less synchronous. To avoid this, we recommend gradually reducing culture density

184 over the course of several days. It is difficult to propose a common benchmark for when, during larval development, to undertake this density reduction. As a rule of thumb, we have found that lowering the density about 1/3-1/2 of the way through larval development seems to yield good results.

Embryos and larvae of species that do not require food to complete metamorphosis (i.e.,

lecithotrophic development) should be cultured at low density from the outset. Such embryos and larvae are often positively buoyant, accumulating at the water surface, and crowded cultures

192 can lead to increased mortality, with subsequent release of yolk and rapid fouling. In open culturing systems, with constant flushing of waste products (see below), the need for low density culture of

194 feeding and non-feeding larvae may not be as critical.

\section{3) Stir or mix cultures gently and constantly}

Mixing of cultures is necessary for optimal larval growth. Mixing oxygenates cultures, helps to maintain consistent temperatures within cultures, and keeps food and larvae evenly distributed in the containers. We present the specifics of mixing and stirring systems in the sections below regarding small, medium and large-scale culturing.

If larvae are reared in replicate experimental vessels, after every water change the position of all vessels in the culture area should be rotated. This allows larvae in the various treatments to experience all possible conditions in the sea table or environmental chamber and helps reduce 
among-container variation (i.e., "beaker effects") during development.

208 4) High quality food in, high quality larvae out

210 Food sources for cultures of planktotrophic larvae vary, but ideally a mixture of live algal species is provided (Castilla-Gavilan, Buzin, Cognie, Dumay, Turpin \& Decottignies, 2018; Ren, Liu, Dong \&

212 Pearce, 2016; Scholtz, Bolton \& Macey, 2013; M.F. Strathmann, 1987; Strathmann 2014). A commonly used mix for tropical and temperate echinoderm larvae includes all three or pairs of the following

214 algae: Rhodomonas lens, Dunaliella tertiolecta and Isochrysis galbana. A blend of Chaetoceros, Chlorella, and Pyranimonas works well with temperate echinoderm larvae (Zhang, Song, Hamel \&

216 Mercier, 2015). Proteomonas sulcata has been used successfully with tropical echinoderm larvae (Wolfe, Graba-Landry, Dworjanyn \& Byrne, 2017). Each algal species can also be used individually,

218 but slower or less synchronous larval development may result.

220 The appropriate concentration of food to add to cultures and the frequency of replenishing food depends on a variety of factors. The goal should be to prevent larvae from depleting their algal food 222 supplies between water and food changes (usually every 1-2 d; see above); larvae should always have visible algal cells in their guts. Most echinoderm larvae cultured at low densities ( $\leq 1$ per $\mathrm{ml}$; see

224 above) grow rapidly at concentrations of 5000-10000 algal cells per $\mathrm{ml}$ (with algal cells of $\sim 10 \mu \mathrm{m}$ in diameter), with food replenished every 2-3 d. However, if larval size or density in cultures is high, or food is changed infrequently, larvae should be provided higher concentrations of food. Likewise, if algae with diameters significantly smaller than $10 \mu \mathrm{m}$ are used, the amount of food should be 228 scaled up proportionately to the volume of the individual algal cells. 
230 To feed larval cultures, briefly and lightly centrifuge algal cultures, discard the supernatant algal growth medium, and resuspend algae in FSW or ASW. Care should be taken to avoid forming too

232 hard a pellet during centrifugation as this will kill algae; dead algae forms a recognizable plume upon resuspension. A few trials will yield an appropriate centrifugation time and speed for

234 concentrating algae using the available equipment. Estimate algal concentration in this stock solution with a hemacytometer or flow cytometer, then add the appropriate volume to each culture vessel to achieve the desired initial concentration. See Strathmann (2014) for further details. Note that a centrifugation step is not technically required, but we recommend it in order to limit the 238 introduction of the algal growth medium into larval cultures.

240 Algae cultures, free of pathogens and contaminants, are imperative to the successful rearing of planktotrophic larvae. There should be regular routine screening and cleaning of stock algae cultures. As needed, new algae cultures can be obtained from a reputable source, (e.g., in the USA the UTEX Culture Collection of Algae and the National Center for Marine Algae and Microbiota,

244 Aqualgae in Europe, and the Australian National Algae Supply Service). F/2 -a medium in which SW is enriched with nutrients, trace elements and vitamins to support algal growth-is an appropriate 246 culture medium for most microalgae (diatoms may require additional compounds, notably silica). FSW or ASW should first be sterilized either by autoclaving or microwaving, and then cooled to 248 room temperature before adding the concentrated components of the $f / 2$ medium (pre-mixed concentrate is available commercially, or can be made from published recipes, e.g., Guillard, 1975), and then inoculating the new medium with algal cells. Cultures typically grow well at room temperature, either under 12:12 grow lights or in indirect light near windows. Stock algae cultures 
252 of many species can be kept as cool as $10^{\circ} \mathrm{C}$ (with grow lights) for long term maintenance. Note that natural plankton can also be used as a food source if algal cultures are unavailable or if more natural

254 feeding regimes are desired. See Strathmann (2014) for more details.

256 While exposure to light is essential for healthy algal cultures, it is not clear that larvae need or benefit from lighting, though this has not been well-studied. Successful larval development has

258 been reported with a variety of light conditions, including ambient light, timed full spectrum fluorescent lights and complete darkness. Milonas, Pernet \& Bingham (2010) report some surprising differences in growth trajectory in echinoid larvae raised in 12:12 light regimes versus those in complete darkness. Montgomery, Hamel \& Mercier (2018) highlighted the role of light intensity and wavelength on larval swimming behavior.

\section{5) Clean cultures gently}

266 Water changes may be accomplished by reverse filtering the water from cultures a mesh size smaller than the size of the larvae. In very small cultures (a few hundred milliliters per container or less), equipment for reverse filtration can consist of a turkey baster and a filter basket (e.g., a plastic beaker with the bottom cut out and replaced with a Nitex mesh screen). In larger cultures $(\geq 0.5 \mathrm{~L})$, we recommend a reverse filtration apparatus like the one shown in Figure 1A: a 50-ml conical tube with a small hole cut in the bottom, and a Nitex mesh screen affixed to the opening. A line of tubing

272 is inserted snugly in the hole in the bottom and into the conical tube (see also Leahy, 1986). The smaller the inner diameter of the tubing, the slower and gentler will be the reverse filtering process.

274 With this method, upwards of $95 \%$ of the culture water can be exchanged at each water change 
(see Fig. 1B). The larvae can then be poured into a smaller vessel for examination in a binocular

276 microscope, or selection of a subset for fixation, biochemical analysis, etc.

278 Forward filtering of larvae, where the entire volume of the cultures is passed through a Nitex filter basket, is often used in medium and large scale culturing systems. We have also successfully used forward filtration in small scale culture of certain robust larvae, as detailed below.

282 Frequency of water changes is dependent on a number of factors, including larval density, rearing temperature and developmental mode (planktotrophy versus lecithotrophy). Detailed suggestions

284 for water change frequency can be found in the sections below on small, medium and large scale culturing methods, as well as in the sections on taxon specific approaches that follow.

When larvae are concentrated during water changes, the researcher may wish to select a few larvae for more detailed microscopic examination. To visualize live, ciliated larvae in a compound microscope, the larvae need to be immobilized but not crushed. Our favored method to accomplish this is to use modeling clay to raise the cover glass slightly above the surface of the slide.

292 First, one or more larvae are transferred along with a small drop of SW onto a slide. Next, the four corners of a cover glass are scraped gently through a soft piece of modeling clay (dry or brittle clay will crack the cover glass during this operation) so that very small amounts of the clay are visible in each of the four corners. This raised cover glass is then lowered gently onto the sample. If the space under the cover glass is too tall, the larvae will continue to swim. In that case, the cover glass can be carefully pressed down until the larvae are trapped but not crushed. After observations, the cover 

have shown that such "post-observation" larvae subsequently develop normally, and at the same rate as their unmanipulated siblings. For other microscopy methods for examining larvae, see M.F. Strathmann (1987) and R.R. Strathmann (2014).

\section{Small-scale culturing methods}

Hundreds to thousands of echinoderm larvae can be cultured in FSW or ASW in 2-4 L containers. Even smaller scale cultures (e.g., $250 \mathrm{ml}$ to $1 \mathrm{~L}$ ) are often desirable when greater numbers of replicates or treatments are needed, though the smaller volumes mean that fewer larvae can be maintained per replicate container. Many species can be kept at room temperature $\left(20-22^{\circ} \mathrm{C}\right)$, but in other cases larvae require cooler or warmer temperatures. In locations where flowing SW is available at the ambient local ocean temperatures, standing culture containers in aquaria work well. Alternate approaches include standing cultures in chilling or heating water baths, or using constant temperature rooms or incubators for cultures.

Stirring in small-scale culture can be accomplished by swinging paddles (Fig. 1C), airlift-droplet stirrers, small rotating paddles (M.F. Strathmann, 1987), or other forms of agitation, such as shaking incubators or gyratory shaker platforms (Aronowicz, 2007). In small-scale closed cultures, we recommend that water changes generally be done approximately every other day, though daily water changes may be required if higher than ideal densities are needed. Daily water changes may 320 also be desired in warmer temperature closed cultures, where evaporation and harmful bacterial 
and protist growth are a greater concern.

The following reverse filtration water change protocol greatly reduces the level of unwanted

324 particles (e.g., decaying algal food) at each water change while minimizing loss of larvae. Such unwanted particles at water changes can interfere with larval feeding (Lizárraga, Danihel \& Pernet,

326 2017) and could be a source for bacterial and protist growth. In this protocol, the remaining water in a culture vessel after reverse filtration is first poured into one bowl. The empty culture vessel is rinsed (e.g., with a squirt bottle) thoroughly with FSW or ASW and those rinses are poured into a second bowl; the reverse filtration apparatus and screen is also rinsed into this second bowl with

330 FSW or ASW. This second bowl will now contain the vast majority of unwanted particles and a handful of larvae, the latter of which can be transferred manually into the first bowl, and the

332 remaining contents of the second bowl discarded. The first bowl can now be further cleaned, if desired, by manual removal of remaining unwanted particles, and then the larvae returned to their 334 cleaned and refilled culture vessel.

336 An alternative protocol is forward filtration, which has been used successfully in small-scale culture of echinoid, asteroid, and ophiuroid larvae (Fig. 2; Leahy, 1986). This technique uses a filter

338 basket made from a beaker with the bottom cut off and replaced with an appropriately-sized Nitex mesh (i.e., significantly smaller in mesh size than the larvae). The filter basket stands in a bowl that is 340 wider and shorter than the sides of the basket. The contents of the culture are gently poured into the basket, the water and waste products are then flushed through the bottom of the basket and into and over the sides of the bowl; the larvae remain in suspension within the basket. The culture vessel is washed, refilled, food is added, and the larvae are returned to the culture vessel. This 
344 forward filtering protocol is rapid, and when done carefully (including daily if needed), results in few larvae being lost. It is also an effective method to lower the density of ciliates or other protists. Note that especially fragile larvae (e.g., ophioplutei with slender arms, such as Ophiotrix spp., and diadematoid plutei) may not be amenable to this forward filtering technique.

An important distinction is whether the embryos and larvae are positively or negatively buoyant.

350 For species with negatively or neutrally buoyant larvae the shaking or mixing methods described above can be applied; modifications are needed for species with positively buoyant larvae

352 (Aronowicz, 2007). For example, yolky embryos and larvae that do not require algal food can be kept in plastic tea infusers where oxygen can enter through the mesh if kept in a larger aquarium or

354 flow-through SW system. Alternatively, embryos and larvae can be enclosed in roller bottle culture systems filled to the brim, and thus without air volume. The larvae will be protected from capture or rupture in the surface tension and from damage by paddles. Longer culture periods between water changes using the roller bottle system have been successfully employed for the planktotrophic sea urchin Lytechinus variegatus (Tom Capo, pers. comm.) with two modifications: (1) larvae are maintained under sufficient light to support continued algae growth within the culture vessels; and

360 (2) the openings of the bottles are secured with parafilm followed by plastic wrap and a rubber band. This latter presumably allows sufficient gas exchange to avoid oxygen depletion, something 362 also provided by the algae included as food.

Short-term culturing (a few days at most) can also be done in multi-well plates, shot glasses or petri dishes. This approach is particularly useful when individual larvae need to be monitored (e.g., for larval cloning; McDonald \& Vaughn, 2010). It is recommended to provide a minimum of $1 \mathrm{ml}$ of 
water with algae per larva and change water daily. If possible, such containers should be agitated,

368 for example, with a shaker platform set to fewer than 80 rotations per minute or with a plankton wheel. For tropical species, water changes using this method may need to be conducted more than once per day to limit harmful bacterial or protist growth. Note that tissue culture-treated multi-well plates should be washed thoroughly before first use, especially taking care to remove the tissue

372 culture treatment from the surface: treated well plates have been shown to be biologically active (Herrmann, Siefker \& Berking, 2003). As above, to avoid negative interactions with plasticware, we recommend glass for long-term cultures when possible.

376 Finally, if flowing SW is available, larvae can be reared in small containers with filter windows to prevent loss of larvae. The larvae are supplied with SW though a dripper tap system. The dripper

378 valves used in garden watering systems are very useful in this context (Kamya, Dworjanyn, Hardy, Mos, Uthicke \& Byrne, 2014). This works well for both planktotrophic and lecithotrophic larvae. For the former, the system can be periodically turned off to allow larvae to feed on added phytoplankton.

\section{Medium-scale culturing methods}

386 If more than a few thousand late stage larvae are required, a medium-scale culturing method may be useful. One such system is pictured in Figure 3: a 75-L cylindrical culturing tank with gentle aeration to maintain gas exchange, prevent stratification and maintain the algae and as many as $20 \mathrm{~K}$ larvae in suspension. At the bottom of the tank is a valve that is opened to drain the tank at 
water changes, every 2-3 d. The water is drained slowly through a Nitex mesh basket of a mesh size significantly smaller than the size of the larvae. The mesh basket (e.g., a large plastic beaker with the bottom cut off and replaced with the appropriately-sized Nitex mesh, or a 30-cm wide plumbing tubing with a Nitex mesh similarly affixed at one end) is taller and narrower than a bucket in which it is sitting. As the water is drained from the tank, it passes through the mesh and into and overflowing the sides of the bucket; the larvae are always maintained suspended in water inside the mesh basket. Once recovered, the larvae can be examined while the tank is cleaned if needed, refilled with FSW or ASW and re-stocked with algae. Then, the larvae are returned to the tank.

Because late-stage larvae of some species might settle on the sides of the column, the researcher employing this system might consider moving late-stage larvae into smaller vessels for settlement and subsequent study.

An alternative method of medium-scale culturing (which can also be modified for small or large 404 scale applications), is a constant flow-through system. Here, there is no need to change water, as clean SW is being constantly circulated through the system. In one design, round 4-L plastic containers with perforated and meshed walls (see below) are placed inside a larger tank supplied with running ambient SW (approximately $20 \mathrm{~L}$ per $\mathrm{h}$ ). This suits laboratory scale cultures in the context of basic (Gianasi, Hamel \& Mercier, 2018a; Montgomery, Hamel \& Mercier, 2017, 2018) and applied research (Gianasi, Hamel \& Mercier, 2018b). The size of the comtainers can be scaled up as needed; black containers provide a darker environment, which may be beneficial both for encouraging settlement in some larvae and for locating recently settled juveniles. In order to ensure 412 a constant flow of SW into the rearing vessels, holes $\left(\sim 40 \mathrm{~cm}^{2}\right)$ are cut out along the walls close to 
the bottom of the round containers and covered with mesh (chosen to be as large as possible while

414 retaining the embryos and larvae). The parameters of the SW are left to fluctuate with ambient conditions, including temperature.

416

The main challenge here is providing food, as food will be flushed through the system at the same

418 rate as the water flow. Two solutions that have proven effective are: 1) a drop-by-drop system where food is provided continuously; and 2) punctuated pulses of food several times a day, with or

420 without temporary cessation of water flow through the cultures during feeding bouts (see Mercier \& Hamel, 2013). As mentioned previously, the best way to determine that an appropriate amount of

422 food is being added in any culturing system is to examine the larvae carefully throughout larval development.

Overall, flow-through culture requires very little maintenance. In systems that use natural SW, the meshed windows must be cleaned weekly to maintain optimum water circulation, and the bottom of the vessels must also be vacuumed (i.e., by siphoning through a narrow diameter tubing), on a 428 regular basis to remove debris and dead embryos and larvae. Note that organisms smaller than the mesh size will inevitably enter such cultures.

\section{Large-scale culturing methods}

434 In an aquaculture context, or if hundreds of thousands of larvae or juveniles are otherwise required, a large-scale culturing technique should be employed. In many ways, larger tanks are more 
436 forgiving and easier to work with than smaller tanks: temperature and $\mathrm{pH}$ tend to be more stable, and there are fewer replicates and tanks to monitor and clean. However, when we move to larger cultures the stakes are higher, with 'more eggs in the same basket.' As tanks get larger, flow dynamics change, which could be a source of stress on larvae or otherwise lead to changes in larval 440 behavior.

442 Simply put, scaling up requires more of everything: food, water, electricity, tanks, space, labor and patience. It is important that pumps, compressors, blowers, pipes, filters and sieves be sized correctly as you increase scale. It is vital that the broodstock is healthy, and that the researcher be conscious of the "Top Five Things" suggested above.

We will give an example here based on the Ānuenue Urchin Hatchery in Oahu, Hawai'i, where the collector urchin Tripneustes gratilla is cultured from egg to juvenile in about $23 \mathrm{~d}$. Larvae are housed in 200-L conical bottom tanks provided with steady but gentle aeration (see Medium-scale culturing methods section, above).

452 The following routine is repeated daily:

- A known volume of water is sampled first thing in the morning to measure overnight phytoplankton consumption and larval density, health and growth.

- Larvae are fed fresh food to hold them until the daily water exchange.

- 200-L tanks (Fig. 4A) are drained down to $100 \mathrm{~L}$ with a Banjo screen filter (Fig. 4B).

- Water is exchanged - using clean, pH adjusted, UV sterilized FSW- at a rate of $5 \mathrm{~L}$ per min for 60 min (i.e., a 300\% water exchange). 
- Tanks are refilled; larvae are fed a base quantity of cultured phytoplankton.

- A water sample is taken 2-4 h later to determine phytoplankton density and estimate feeding rate.

- If necessary, larvae are fed again at the end of the day.

464 Care must be taken during water exchanges and tank changes to insure that larvae do not get injured or stuck to sieves or screens. Therefore, if higher draining rates are required, a greater 466 surface area of the sieve or mesh is needed.

Large-scale culture vessels need to be cleaned and sanitized regularly, while ensuring that larvae never come into contact with cleaning agents. Chlorine, iodine or acid may be used to sanitize equipment. Any of these or ozone may be used to clean plumbing. Viricides such as Virkon Aquatic may be used in footbaths and to sanitize walls and floors in larval labs as well as phytoplankton labs.

472 One effective protocol is to use $12.5 \%$ sodium hypochlorite (bleach) for most disinfecting procedures: it is inexpensive, easily acquired, approved for use in agriculture and food systems, can

474 be neutralized with sodium thiosulfate, and is quite effective. Appropriate protective equipment should be worn.

With larger systems, it is important to implement "clean in place" methodologies, including 478 benchtops and the 200-L tanks. When possible, the entire system should be sanitized from end to end. Saltwater plumbing and aeration supply plumbing should be cleaned frequently. Saltwater supply lines can be flushed with freshwater daily and should be sterilized between larval cycles, as should aeration systems. Smaller, unattached parts of the system should be broken down and 
placed in a chlorine bath, including sieves, beakers, pitchers, Banjo screens, and siphon tubes. It is just as vital to make sure that all equipment is free from bleach before putting it back into service 484 (Hill, Berthe, Lightner \& Sais, 2013).

486 Note that the example outlined above is rather modest in size relative to many aquaculture operations, which can use 1000 to 20000 -L tanks (or even greater) for larval culture, for instance

488 those employed for the culture of commercial holothuroids (e.g., Mercier \& Hamel, 2013; Yang, Hamel \& Mercier, 2015). Either regular water changes and siphoning of the bottom of the tanks to remove dead larvae and debris are performed every other day (with similar methods as described above), or a flow-through system of SW exchange is used. To minimizes manipulations and decreases stress to the larvae, some laboratories start the culture in vessels that are only one third full and simply add more FSW or ASW at regular intervals until the vessel is full, after which water changes can be made for the remainder of the culture period (Zhang et al, 2015).

\section{TAXON SPECIFIC APPROACHES}

In the following sections, we detail specific advice and approaches for culturing larvae of the four 500 most-studied classes of echinoderms: the Asteroidea (sea stars), Echinoidea (sea urchins, sand dollars and kin), Holothuroidea (sea cucumbers) and Ophiuroidea (brittle stars and basket stars).

502 Note that many of the methods outlined below in a given section might apply equally well to larvae from the other three classes. For information on collection, spawning, and fertilization of each of 
these four classes, see Chapter 1 in this volume on "Obtaining animals and gametes for embryological studies of echinoderms". See also Chapter 6 in this volume for more details on the sea urchin Lytechinus pictus. Because of the dearth of studies (especially recent studies) on Crinoidea (feather stars and sea lilies; the fifth extant echinoderm class), and in the interest of space, we here 508 refer the interested reader to Holland (1991), Balser (2002) and Amemiya, Hibino, Nakano, Yamaguchi, Kuraishi \& Kiyomoto (2015), and references therein.

\section{Asteroidea}

Asteroid echinoderms typically develop via either feeding or non-feeding planktonic stages, or in

514 benthic broods protected by a parent. All species with feeding (planktotrophic) larvae develop through a bipinnaria stage; most also have a subsequent brachiolaria stage (McEdward \& Miner,

516 2001; Fig. 5). Non-feeding (lecithotrophic) planktonic stages are diverse in developmental pattern, form, and nomenclature (McEdward \& Janies, 1993; McEdward \& Miner, 2001).

Rearing planktotrophic sea star larvae

Establishing cultures. The embryos of sea stars with feeding larvae are ready to be distributed into culture vessels when they hatch (as swimming blastulae or gastrulae, depending on species), approximately 2-4 d post fertilization ( $\mathrm{dpf}$ ) for tropical and temperate species.

Providing larval food. Sea star larvae can capture and ingest particles of a wide range of shapes and 526 sizes (R.R. Strathmann, 1971, 1987). Cells of many easily cultured micro-algae can thus be used as 
food, as detailed above (see Top Five Things section).

Cleaning cultures. Sea star larvae are somewhat delicate and can be damaged during cleaning, causing mortality and even cloning in some species. As a compromise, most larval biologists clean and feed cultures every 2-3 d, though if avoidance of mortality is critically important, longer intervals are possible (Bashevkin, Lee, Driver, Carrington \& George, 2016). The flow-through dripper tap system (see Small-scale culturing methods section, above) significantly reduces the buildup of dead larvae, waste material and bacteria, and thereby reduces the need for frequent cleaning.

536 Cleaning may be achieved by reverse or forward filtration (see above), always being careful to minimize turbulence and contact of larvae with filtering surfaces to reduce damage to the larvae.

538 Once concentrated, larger larvae can be picked out of the container one by one with a large-bore pipette and transferred to fresh FSW or ASW in a clean culture vessel (i.e., a 100\% water exchange). If larvae are sufficiently large and swim to the surface when stirring is paused, then the reverse/forward filtration step can be skipped, and larvae picked out from the surface with a

542 pipette, as above. Direct transfer is an excellent way to keep track of the total numbers of larvae. Nevertheless, for cultures of hundreds or more larvae per container, direct transfer is likely 544 impractical, and bulk culturing methods (as described above) can be employed.

546 Rearing lecithotrophic sea star larvae

548 Establishing cultures. Like feeding larvae, the embryos of sea stars with non-feeding larvae can be distributed into culture vessels when they hatch, typically as swimming blastulae, $\sim 4-5$ dpf for 
temperate species or 1-3 dpf for tropical and subtropical species (Birkeland, Chia \& Strathmann, 1971; Chen \& Chen, 1992; Chia, 1966; M.F. Strathmann, 1987). These embryos are often positively

buoyant, so proximity to the water surface is not a good indication that they have hatched. The larvae can be maintained in small volumes of FSW or ASW in glass bowls or plastic tissue culture

554 dishes with culture temperature carefully controlled. Gentle stirring may help to keep delicate larvae out of the surface tension, as can frequent dripping of water on to the surface of the culture

556 vessel (Aronowicz, 2007), as well as the addition of small amounts of cetyl alcohol (Hurst, 1967). Note that some lecithotrophic sea star larvae do not encounter problems when at the surface per se, but do have problems at the surface-vessel interface, as the larvae can adhere to the sides of the vessel.

For medium-scale culturing of non-feeding larvae of sea stars, please refer to the general section on

562 Medium-scale culturing methods, above.

564 Cleaning cultures. If cultures of non-feeding larvae are low in larval density, cleaning should be carried out quite infrequently (1-2 times per week) to minimize the risk of damaging larvae. Instead 566 of allowing them to contact filtering meshes, it is best to either gently transfer these larvae one by one by wide-bore pipette (easily done, as they are typically quite large and brightly colored) or use beakers or other vessels smaller than the size of the culture vessel to gently scoop up the buoyant larvae and then transfer them to clean FSW or ASW. Higher temperature cultures require more

570 frequent transfers.

572 There are also diverse taxa of brooding asteroids that offer easy access to all developmental stages 
through the crawl away juvenile. These species range from external brooders that care for their

574 young under the oral surface (e.g., Leptasterias spp.; Fig. 6) to the viviparous asterinids that give birth to juveniles (e.g., Parvulastra vivipara and Cryptasterina hystera) (Byrne, 1996, 2005; George, 576 1994).

578 Induction of settlement, completion of metamorphosis and early juvenile growth

580 Competent larvae of asteroids with planktotrophic and lecithotrophic development settle readily in response to a biofilm on the surface of the culture container or other surfaces such as shell

582 fragments placed in the containers. The competent larvae of many species appear to settle particularly well in response to the addition of coralline algae, including the crustose form on small

584 rocks and geniculate algal fragments (Fig. 7). These substrates are useful as the newly metamorphosed juveniles can be transferred to new containers by picking up the shells, small rocks 586 or pieces of algae.

588 Asteroid juveniles start life as predominantly herbivores feeding on biofilms and algae, with some becoming predators with time (Martinez, Byrne \& Coleman, 2017). Thus, to rear juvenile asteroids, it

590 is important to renew the algae or shell fragments with biofilm regularly to ensure enough food. However, as in adult asteroids, we have noticed that cannibalism by juveniles can occur within as

592 few as $3 \mathrm{~d}$ post-metamorphosis, even when food is provided. Therefore, maintaining juvenile asteroids for study should be done at very low densities. 
The ability to generate 1000's of juveniles by rearing the benthic larvae of direct developing species

596 such as Leptasterias hexactis Stimpson and Parvulastra exigua Lamarck provide the easiest way to access asteroid juveniles for study (Fig. 6; Byrne, 1995; George, 1994; Hodin, 2006).

600 Echinoidea

602 History of echinoid larval culturing

604 Echinoids have perhaps the richest history of marine invertebrate larval culturing. The first microscopic observation of fertilization was in sea urchins (Derbès, 1847), and Müller (1846) coined

606 the term "pluteus" (L: easel) to describe the larval form. Echinoids serve as the stereotype for deuterostome development (Pearse \& Cameron, 1991). Mortensen published extensive

608 observations of larval development on tropical taxa $(1921,1931,1937,1938)$ and summarized (1921) prior echinoderm larval rearing accomplishments, mainly using European, Scandinavian or 610 Mediterranean taxa. Mortensen reared larvae without providing food, transferring larvae to fresh SW (thus containing the natural assemblages of food) every day to few days, which he described as

612 quite laborious, and he recounts an experience in Mauritius in which his cultures died due to the use of harbor water that was polluted with sewage (Mortensen, 1931). His culturing experiences

614 appear to have hinged on the same factors as those of modern researchers: frequent water changes with fresh, clean SW, and abundant food (Leahy, 1986).

More recently, echinoid larvae have emerged as useful subjects for studies of swimming and 
618 feeding (Strathmann \& Grunbaum, 2006; Wheeler, Chan, Anderson \& Mullineaux, 2016), physiology and metabolism (Leong \& Manahan, 1997; Marsh, Maxson \& Manahan, 2001), ocean acidification

620 impacts (Dupont, Ortega-Martínez \& Thorndyke, 2010), immune systems (Ho, , Buckley, Schrankel, Schuh, Hibino, Solek et al, 2016) and larval cloning (McDonald \& Vaughn, 2010), among other topics.

622 Microscopic methods (preservation and various labeling methods) have improved significantly in recent years (Strickland, von Dassow, Ellenberg, Foe, Lenart \& Burgess 2004), including a method

624 that maintains intact skeletal elements during long-term storage (Emlet, 2010; Turner, 1976). Larval and juvenile skeleton (in all echinoderms) can be visualized by an inexpensive modification of any compound microscope with cross-polarized light (e.g., see Figs. 8C, 9D, 12A and 14C,D below; M.F. Strathmann, 1987)

Rearing planktotrophic echinoid larvae (echinoplutei)

The dominant life-history mode among echinoids is obligate planktotrophy, where adults release many small eggs $(<250 \mu$ m diameter, averaging $\sim 100-125 \mu \mathrm{m})$ that give rise to pluteus larvae (Fig. 8) that must feed on phytoplankton for a time in order to attain sufficient energy to complete 634 metamorphosis (reviewed in McEdward \& Miner 2001; Soars, Prowse \& Byrne, 2009). This obligate feeding period can last from days to a year or longer, depending on egg size, food levels and developmental temperature. Planktotrophic echinoid larvae tend to develop quite synchronously to the stage at which they are competent to settle, making them a good choice for a variety of studies ranging from larval physiology to the impact of stressors (such as ocean acidification) on larval development. 
Planktotrophic larvae reared in low food, near starvation conditions (generally accepted to be less

642 than 500-1000 algal cells per $\mathrm{ml}$ ) respond by growing relatively longer feeding structures -the skeleton-supported larval "arms" that extend and support a continuous ciliated feeding band. This

644 response is one of the best-studied examples of phenotypic plasticity among marine invertebrates (reviewed in McAlister \& Miner, 2018) and may be associated with the evolutionary transition to

646 lecithotrophic development in some groups (Strathmann, Fenaux \& Strathmann, 1992). The relative ease of measuring arm length in these larvae offers precise quantitative measures of larval growth and quality, and makes echinoid larvae a beneficial choice for a wide range of manipulative experiments.

Developmental staging in echinoplutei

Development proceeds post-fertilization through identifiable embryonic stages, hatching as 654 blastulae, followed by gastrulation, prism (body skeletal rods present), and the early pluteus capable of feeding (Kumé \& Dan, 1968). The timing of development to each stage varies by species 656 and rearing temperature, but most species will attain the early pluteus stage at about 2-5 dpf.

658 Early pluteus larvae have two pairs of arms (the "4-arm stage"), the longer postorals (PO) and the anterolaterals $(A L)$, which is followed in most species by a 6- and then an 8-arm stage (see Smith, 660 Smith, Cameron \& Urry, 2008). There is considerable evolutionary diversity of echinopluteus morphology with some species possessing 10 arms (e.g., Fig. 8A) or even 12 arms, single or dual 662 posterior arms, terminal spines that may assist in defense, as well as fleshy, ciliated vibratile lobes or epaulettes, that develop late in development and increase swimming speed (Fig. 8; Emlet, 1988; 
Hart, 1991; Strathmann, 1971; Wray, 1992). Some species within the family Diadematidae have a particularly distinct larval form, termed "Echinopluteus transversus" (Fig. 8G; Huggett, King, Williamson \& Steinberg, 2005; Mortensen, 1921, 1937; Soars et al, 2009), and characterized by strikingly long PO arms (up to several mm's long) with all other arms highly reduced ( $\mathrm{AL}$ ) or absent 668 (PD and PR).

One benchmark that can be used to determine the stage at which larval density should be lowered is the first appearance of juvenile specific structures. In most echinoids (cidaroids are an exception), this stage is visible as the timing of invagination of the echinus rudiment (rudiment soft tissue stage $i$ in Heyland \& Hodin, 2014), which will contribute to the ectoderm of the juvenile, and is generally reached at approximately $30-50 \%$ of the way through the larval period when the larvae are fed ad libitum.

Development of structures fated to form the juvenile proceed in parallel to larval development, the timing of which varies by species and with amount of food provided. This is a second aspect of the phenotypic plasticity alluded to above: high food causes larvae to proceed with juvenile structure development at the expense of larval arms. Heyland \& Hodin (2014) have dissected formation of the juvenile structures in the purple sea urchin Strongylocentrotus purpuratus (Fig. 8C) into 8 soft tissue 682 stages and 10 juvenile skeletal stages. Subsequent studies have revealed that this basic scheme applies to a wide diversity of echinoids, although there are interesting variations among taxa (e.g., 684 Kitazawa, Kobayashi, Kasahara, Takuwa \& Yamanaka, 2012) as well as heterochronies during larval development (J. Hodin, unpublished), and once juveniles have emerged (Burke, 1980, Emlet, 2010). 
Rearing lecithotrophic echinoid larvae

688

Non-feeding (lecithotrophic) development is found in approximately $20 \%$ of extant echinoid species; including extinct taxa it has been estimated to have evolved independently in a minimum of 14 lineages (Wray, 1992; Wray \& Bely, 1994; Wray \& Raff, 1991). Compared to the elaborate feeding morphology of planktotrophic echinoplutei, lecithotrophic larvae are highly derived, morphologically simple and convergent across taxa (Wray, 1992; Wray \& Raff, 1991). One well studied species is Heliocidaris erythrogramma, which has a highly reduced larva that develops from large eggs and metamorphoses in 3-6 d, quite unlike its planktotrophic cousin, $H$. tuberculata (Fig. 696 8E,F; Byrne, Emlet \& Cerra, 2001). This change in life history is accompanied by apparent shifts in the embryonic fate map, cleavage patterns, process of formation of juvenile structures and corresponding gene expression (Israel, Martik, Byrne, Raff, Raff, McClay et al, 2016; Wray \& Raff, 1989). There are also diverse taxa of brooding echinoids with crawl away juveniles, such as the lantern urchin Cassidulus caribbaearum (Fig.9; Gladfelter, 1978; Hodin, 2006).

704 As far as we are aware, all echinoids that have been tested respond to "excess" potassium in SW by completing their transformation from larva to juvenile (n.b., excess potassium is potassium added

706 above the background concentration). The concentration of potassium chloride (KCl) that elicits this effect does vary among taxa from $40 \mathrm{mM}$ excess $\mathrm{KCl}$ in the NE Pacific sand dollar Dendraster excentricus to $120 \mathrm{mM}$ excess in the Hawai'ian shingle urchin Colobocentrotus atratus (Table 1). We recommend that the researcher studying a species not mentioned in Table 1 expose larvae to a 
710 range of $\mathrm{KCl}$ concentrations to determine the minimum effective dose for that species. We recommend a $1 \mathrm{~h}$ exposure to excess potassium followed by transfer into clean FSW or ASW for

712 recovery and completion of metamorphosis.

714 One disadvantage of excess potassium exposure is that it stuns the larvae, so they do not exhibit the normal progression of pre-settlement behaviors (see Bishop \& Brandhorst, 2007); in that sense, the process seems somewhat short-circuited. We therefore recommend that whenever possible, researchers attempt to find "natural inducers": namely, the kinds of compounds or substrates that

718 larvae might respond to in the field. Nevertheless, our unpublished observations indicate that there is little to no difference in growth and survival of $S$. purpuratus juveniles during the week after recovery from $\mathrm{KCl}$ exposure (70 $\mathrm{mM}$ excess) when compared to those settling in response to a natural inducer (in this case, fronds of the coralline alga Calliarthron tuberculosum Postels \&

722 Ruprecht).

724 Natural inducers tend to be quite species-specific; therefore reviewing the entire spectrum of natural inducers for echinoids is beyond the scope of this chapter. In some cases, larvae settle readily in response to microbial biofilms (reviewed in Hadfield, 2011), sometimes grown in the presence of conspecifics. In other cases, the triggers appear to be specific types of benthic algae, often coralline algae (though in most cases the possibility that the trigger is a specific biofilm growing on the surfaces of these algae has not been excluded; Hadfield, 2011). Histamine, a

730 compound released by macroalgae, appears to be an effective settlement trigger in a variety of echinoids, in some cases at concentrations that have been measured in the field near to the source 732 algae (Swanson, Byrne, Prowse, Mos, Dworjanyn \& Steinberg, 2012). In S. purpuratus, histamine 
exposure modulates competence to settle rather than triggering settlement per se (Sutherby,

734 Giardini, Nguyen, Wessel, Leguia \& Heyland, 2012). For various sand dollars, settlement can be triggered by sand from aquaria housing adults (Allen, 2012; Highsmith, 1982; Highsmith \& Emlet,

736 1986; Vellutini \& Migotto 2010). For the NE Pacific sand dollar, D. excentricus, a specific peptide released from adults into the sand appears to be the trigger (Burke, 1984); but a simple SW extract

738 of the aquarium sand is highly effective (Hodin, Ferner, $\mathrm{Ng}$, Lowe \& Gaylord, 2015; Hodin, Ferner, $\mathrm{Ng}$ \& Gaylord 2018).

Echinoid settlement and the drastic morphological changes associated with the completion of

742 metamorphosis can be observed in real time under a dissecting or compound microscope after settlement has been induced. In most echinoids the major events of this process (Bishop \&

744 Brandhorst, 2007) are completed within a few hours.

746 Early juvenile rearing

748 Most echinoids settle a few days to a week or so before their juvenile mouths open, during which time they use up endogenous reserves from the larva. Once their mouths are open, they are more or

750 less ready to begin feeding (Fadl \& Heyland, 2017; Gosselin \& Jangoux, 1998; Miller \& Emlet, 1999). At that point, in particular with juveniles deriving from planktotrophic larvae, juveniles need to be

752 transferred onto natural biofilms or cultures of benthic diatoms such as Navicula or Nitzschia species, or they will soon die of starvation (Xing, Wang, Cao \& Chang, 2007). Pure cultures of a

754 variety of benthic diatoms can be obtained, for example, from the UTEX Culture Collection of Algae (TX, USA), the National Center for Marine Algae and Microbiota (ME, USA), the Australian National 
756 Algae Supply Service and Aqualgae (Spain/Portugal). Either flowing sea water or frequent water exchanges appear to be required for good growth and survival during the critical first weeks following settlement, during which time juveniles can grow quite rapidly. Eventually juveniles can be transitioned from biofilm/diatom cultures to small pieces of adult food (macroalgae and kelp). Leahy (1986) recommends feeding diatoms to S. purpuratus juveniles for 2 weeks, then transitioning the juveniles to rocks covered with natural biofilm for 1 month, then to pieces of thin seaweed such as the sea lettuce Ulva for 1-2 months, and then ultimately to pieces of kelp.

\section{Holothuroidea}

Holothuroid echinoderms, commonly called sea cucumbers, exhibit a diversity of reproductive strategies from small, poorly-provisioned, unprotected pelagic propagules to large, abundantlyprovisioned, brood-protected benthic propagules, and nearly everything in between. However, the majority of species can be classified as either planktotrophic (producing small, feeding larvae) or lecithotrophic (producing large, non-feeding larvae).

Of the approximately 1400 sea cucumber species described so far, around 80 are harvested commercially (Purcell, Mercier, Conand, Hamel, Toral-Granda, Lovatelli et al, 2013). They are a valuable commodity in many countries of Asia, the Americas, and the tropical Indo-Pacific, where they are mainly processed for trade on Chinese markets (Hamel \& Mercier, 2008a; Toral-Granda, Lovatelli \& Vasconcellos, 2008; Yang et al, 2015). Today, many sea cucumber populations are overexploited and some species are listed as endangered on the IUCN Red List (Purcell, Polidoro, 
Hamel, Gamboa \& Mercier, 2014). Apart from their commercial importance, sea cucumbers are

780 ecologically significant members of benthic communities (Purcell, Conand, Uthicke \& Byrne, 2016) and they are a promising subject for studies of their remarkable regenerative abilities (Zhang, Sun,

782 Yuan, Sun, Gao, Zhang et al, 2017). Therefore, interest in the development of breeding programs for sea cucumber is trending upward, and knowledge of larval development has been gathered from a

784 diversity of tropical and temperate species in the context of scientific research and hatchery production.

Here we summarize the rearing protocols that have been developed to date, chiefly for commercial 788 sea cucumbers, including the top three planktotrophic aquaculture species (Apostichopus japonicus Selenka, Holothuria scabra Jaeger and Isostichopus fuscus Ludwig; Fig. 10A,B), and two other commercially harvested species, one planktotrophic (Apostichopus californicus Stimpson), and one lecithotrophic (Cucumaria frondosa Gunnerus; Fig. 10C,D). Additional information will relate to an unusual lecithotrophic species with no commercial interest (Psolus chitinoides Clark) and a brooding species that does not produce dispersing larvae (Leptosynapta clarki Heding).

Rearing planktotrophic sea cucumber larvae

Larval cultures may follow two main protocols: most use closed conditions and water changes at regular intervals, although some use flow-through (open) conditions. Ultimately, the quality of the water supply is the primary determinant of success.

Culture. The developmental biology of planktotrophic sea cucumber species is very consistent: the 
auricularia larva metamorphoses through a doliolaria stage into a pentactula. The various

developmental stages have been outlined for I. fuscus (Fig. 11; Mercier, Ycaza and Hamel, 2004), H. scabra (Agudo, 2007; Hamel, Pawson, Conand \& Mercier, 2001) and A. japonicus (Qiu, Zhang, Hamel \& Mercier, 2015). In most hatcheries, larvae are cultured in opaque conical tanks with central

806 draining; smaller vessels are used in many laboratories (see above). Full details of commercial culture methods have been summarized previously (Mercier \& Hamel, 2013; Zhang et al, 2015).

808 Generally, early embryos are stocked at densities that do not exceed 1-5 individuals per ml due to density-dependent mortality (Sui, 1990), asynchrony and delayed growth in high densities, and even embryo fusion, which among other things increases developmental asynchrony in cultures (Gianasi et al, 2018a).

Please refer to the General Culturing Methods above for recommended larval densities and water

814 changes in closed cultures, and from small to large scale. Good results can also be obtained under flow-through (open) cultures with $200 \%$ or more water renewal every day. Under both closed and

816 flow-through conditions, siphoning the bottom to remove dead larvae, detritus and bacterial mats is crucial.

We recommend gentle aeration to maintain oxygen levels and to provide mixing of the cultures

820 (Mercier \& Hamel, 2013; Zhang et al, 2015); one should avoid fine bubbles that may obstruct the digestive tract of some larvae. The optimal adjustments for $\mathrm{pH}$, temperature, salinity, and dissolved 822 oxygen are species-specific, but typically, water pumped in from offshore locations in the regions where the adults are found is sufficient to promote good larval cultures. 
Feeding. All planktotrophic species need to be fed micro-algae until they reach the doliolaria (non-

826 feeding) stage. The algal cultures should be of high quality and free of bacteria and copepods; locally available strains provided as a mix of species may yield better results in some cases than 828 monocultures. The most common species of micro-algae used are Dunaliella euchlaia, Chaetoceros gracilis, C. muelleri, C. calcitrans, Phaeodactylum tricornutum, Rhodomonas salina and Tetraselmis 830 chuii.

832 A number of investigators and hatcheries use alternative sources of food when live algae are not available or deemed too costly. Commercial marine micro-algae have been used successfully (Hair,

834 Pickering, Meo, Vereivalu, Hunter, Cavakiqali et al, 2011). Exact mixes and densities of food deemed to optimize larval health and growth are species-specific (Mercier \& Hamel, 2013). Researchers

836 should monitor larvae to ensure that algal cells are found in their digestive tract, at which point, adding more algae is not required; larvae of sea cucumbers collected from the field rarely exhibit full digestive tracts, and thus probably do not require much food to survive. Indeed, overfeeding can quickly lead to fouling of the culture vessels under closed conditions. Under flow-through 840 (open) conditions, cultures can be maintained with a continuous drop-by-drop supply of algae or via daily meals (Mercier \& Hamel, 2013).

Health. Diseases can develop in embryos and larvae, particularly when culturing at larger scales. $A$. 844 japonicus is by far the most extensively cultivated species with billions of larvae produced annually (Yang et al, 2015) and is (unsurprisingly) also the species with the highest number of reported 846 problems. Central to culture issues is the accumulation of excess food, feces, and harmful microorganisms. Symptoms dubbed 'rotting edges', 'stomach ulceration' (auricularia stage), and 
'gas bubble disease' are the most common. The best way to avoid or mitigate these problems is prevention, careful monitoring to remove the first affected individuals, or use of antibiotic and other treatments when available (Mercier \& Hamel, 2013).

852 The most pathogenic agents reported in cultures of $H$. scabra are bacteria causing ectoderm ulceration (Eeckhaut, Parmentier, Becker, Gomez Da Silva \& Jangoux, 2004). The most common 854 culprit identified in lesions are Vibrio sp., Bacteroides sp. and a-Proteobacterium (Becker, Gillan, Lanterbecq, Jangoux, Rasolofonirina, Rakotovao et al, 2004). In the case of I. fuscus, infestation of the

856 digestive system of early larvae by protozoan parasites is the most common (Mercier, Ycaza, Espinoza, Haro \& Hamel, 2012). In the worst cases, the digestive tract completely shrivels up and

858 disappears, which is usually fatal. Although antibiotics and chemicals [e.g., ethylenediaminetetraacetic acid (EDTA)] have been used to mitigate these problem in commercial 860 settings, they are not generally recommended (Zhang et al, 2015). Larger larval cultures of sea cucumber can be plagued by copepod infestations, which are presumed to compete for food and 862 directly damage the larvae.

864 Rearing lecithotrophic sea cucumber larvae

866 While it may be achieved under closed conditions with regular water changes (see above), the culture of sea cucumber propagules is optimal in a flow-through system (see Medium-scale culturing methods, above) with $200 \%$ or more daily turnover of ambient SW. Exposing propagules early in their development to natural conditions not only increases survival rates, but also yields 870 healthier propagules that are strong enough to be released back in the ocean or in pens for grow 
out. For sea cucumbers, survival rates between fertilization and settlement may increase from 1-3\%

872 (typical of closed culture) to 15-40\% (under flow-through), depending on the other culture parameters (Mercier \& Hamel, 2013).

Culture. The major peculiarity of lecithotrophic development, apart from the larger size of the non-

876 feeding larvae, is that the typical auricularia larval stage of planktotrophic sea cucumber species is absent, and the doliolaria stage is often replaced by a vitellaria. C. frondosa is very likely the most

878 studied lecithotrophic sea cucumber, and can thus serve as a case study (Fig. 10C,D; Hamel \& Mercier, 1996). This species is found on hard substrates in cold waters across the North Atlantic and 880 Arctic (Hamel \& Mercier, 2008b). Embryos of $C$. frondosa are typically incubated at densities of $\sim 0.4$ embryos per $\mathrm{ml}$ in round 4-L plastic containers with black bottom and walls (perforated and meshed; see Medium-scale culturing methods, above), which are placed inside a larger tank supplied with running ambient SW (20 L per h). With C. frondosa the rearing temperature generally varies between $\sim 1^{\circ} \mathrm{C}$ during the late winter spawning to $\sim 5^{\circ} \mathrm{C}$ at the time of settlement. For an effective small-scale method of culturing of lecithotrophic sea cucumbers in multiple replicates, see 886 Aronowicz (2007).

\section{Brooding species}

890 Embryos and juveniles of the burrowing sea cucumber L. clarki from the NE Pacific have been used to study the developing nervous system. After collection by sifting sediment, this species can be 892 easily maintained in the lab and broods can be collected and studied during their reproductive season. Their size, optical clarity and relatively fast development (days) makes them ideal organisms 
894 for whole mount observations (Hoekstra, Moroz \& Heyland, 2012).

896 Induction of settlement, completion of metamorphosis and early juvenile growth

898 The goal of larval cultures is often to rear them to settlement; in the case of hatcheries, this is the main goal. At temperatures between $20-25^{\circ} \mathrm{C}$, settlement occurs after about $12-16 \mathrm{dpf}$ in $A$.

900 japonicus and H. scabra (Hamel et al, 2001; Qiu et al, 2015), and 21-27 dpf in I. fuscus (Mercier et al, 2004). While some of the larvae in the three species will settle without stumulation, conditioned

902 surfaces can increase the number of larvae that successfully settle (Mercier \& Hamel, 2013); similar observations have been made in A. californicus (approximately $30 \mathrm{~d}$ to settlement at $14^{\circ} \mathrm{C} ; \mathrm{C}$. Lowe, 904 pers. comm.) and other NE Pacific species. When planktotrophic sea cucumber larvae reach the doliolaria stage, they are approaching competence to settle, which occurs at the subsequent 906 pentactula stage.

908 In both lecithotrophic and planktotrophic species, early juveniles do require a food source. If the system supplying SW to the rearing tanks does not have any filtration, then natural plankton (e.g.,

910 small ciliates, flagellates, diatoms and copepod nauplii) and suspended organic material present in ambient SW will be available. Attempts to mimic the natural habitat are a good idea; in the case of

912 C. frondosa, small rocks often covered with coralline algae can be spread evenly inside the rearing tanks to provide shelter and substrate that will favor settlement (Hamel \& Mercier, 1996) and

914 promote health in early juveniles (Gianasi et al, 2018b). 


\section{Ophiuroidea}

918

There are two main larval types found among ophiuroids with larval development: the

920 ophiopluteus and the vitellaria (compare Fig. 12A and C; Brooks \& Grave, 1899; Byrne \&

Selvakumaraswamy, 2002; Fenaux, 1969; Hendler, 1975, 1991; McEdward \& Miner, 2001; Mortenson,

922 1921, 1938; Stancyk, 1973). The ophiopluteus is primarily a feeding (planktotrophic) larva, but in several species, a non-feeding (lecithotrophic) ophiopluteus is present (Allen \& Podolsky, 2007;

924 Hendler, 1991; Mladenov, 1979) and there is one report of a facultatively-feeding ophiopluteus (Allen \& Podolsky, 2007). The vitellaria larva is obligately lecithotrophic and it is the more common 926 non-feeding larval form (Cisternas \& Byrne, 2005).

928 Developmental patterns in ophiuroids with larval development are broadly categorized based on the predominant larval form (ophiopluteus vs. vitellaria), feeding type (feeding vs. non-feeding

930 larva) and the pattern of metamorphosis that the larva undergoes to give rise to the juvenile (Fig. 13; Byrne \& Selvakumaraswamy, 2002; Cisternas \& Byrne, 2005; Hendler, 1975, 1991; McEdward \&

932 Miner, 2001). Ophiuroids that do not develop through a free-living (pelagic, benthic or encapsulated) larva, instead brood embryos internally which are later released from the parent as 934 advanced juveniles (Hendler, 1991).

936 Rearing planktotrophic ophiuroid larvae (ophioplutei)

938 For planktotrophs, low densities are recommended, in particular at late stages of development. Larval cultures require either very gentle stirring with paddles (as described above) or gentle 
rocking; we recommend the latter for ophioplutei that have long and slender arms such as those of Ophiothrix species (e.g., Fig. 12B). Because most ophioplutei are quite fragile and the arms may

942 break easily, we suggest that densities be reduced to 1 larva per $\mathrm{ml}$ or lower as development progresses and lower still as larvae near metamorphic competence. Similarly, water changes can be 944 reduced to every four days maximum or once a week to reduce any damage caused by handling. Depending on the amount and frequency of food added, these water changes may need to be 946 adjusted accordingly. When larvae are subject to high food regime, more frequent water changes are necessary to prevent a build-up of ciliates in the culture.

Water changes. For reverse filtration (see above) the size of the mesh should be at least $50 \mu \mathrm{m}$ less than the maximum diameter of the larval body and arms so as to avoid passing the larvae through the mesh. Before aspirating water through the filter (and after removal from the stirring mechanism), one should let the larvae sink down from the top of the water surface to about $1 / 3$ down the water column. This will reduce damaging the larvae in the filtration process and minimize 954 the chance of larvae being caught on the underside of the mesh. For fragile larvae, we recommend retaining a greater proportion of the water in the vessel so that larvae are not damaged by excessive 956 concentration and contact with the filters. Ideally, containers, paddles and other equipment should be washed in hot tap water at least once a week during the culturing process to avoid biofilms from 958 forming.

960 Advanced ophioplutei metamorphose while suspended in the water column and these can be easily identified by changes in the shape of the larval body: degeneration of larval arms, with the 962 exception of the two posterolateral arms, reduction in the oral hood and mouth opening, increasing 
opacity of the central portion of the larval body, and appearance of the star-shaped juvenile

964 rudiment (Fig. 14; Byrne \& Selvakumaraswamy, 2002; Selvakumaraswamy \& Byrne, 2006). At this stage larvae are usually located in the mid-water column, and care should be taken when removing water as the posterolateral arms are easily broken.

968 Cloning by ophioplutei. A new ophiopluteus can develop by cloning from the tissue suspended between the posterolateral arms that are released by the juvenile at settlement (Fig. 14; Balser, 1998), as has been recorded in Ophiopholis aculeata and unidentified ophioplutei found in the Gulf Stream off Florida.

Food sources and feeding regime. A mixed diet containing microalgae and diatoms is more 974 commonly used for feeding ophioplutei but single strain diets may also be used (Mladenov, 1985; Podolsky \& McAlister, 2005; Selvakumaraswamy \& Byrne, 2000; Yamashita, 1985). The most commonly used algae (in the 2-15 $\mu$ m diameter range) include Dunaliella tertiolecta, Amphidinium earterae, Isochyrsis galbana, Isochyrsis sp, Rhodomonas spp., Tetraselmis chuii and diatoms like

978 Chaetoceros calcitrans, C. gracillis, C. muelleri, Pavlova viridis and Phaeodactylum tricornutum. The optimal diet including a mix of strains, densities, particle sizes and other factors are as yet to be 980 determined. Cultures are typically fed every $2 \mathrm{~d}$, with suggested densities (based on 5-10 $\mu \mathrm{m}$ algal cells) of approximately $7.5 \times 10^{3}$ cells per ml every two days for ophioplutei of tropical species (Allen 982 and Podolsky 2007) and $2 \times 10^{4}$ cells per ml every four days for larvae of temperate species (Selvakumaraswamy \& Byrne, 2000). 
For ophiuroid species with non-feeding larvae, embryos can be distributed into containers with FSW 988 or ASW after fertilization. The embryos and larvae need gentle agitation (rocking or bubbling from a pipette) to break the surface tension and to prevent damaging embryos. They can also be maintained at low densities (1 larva per $\mathrm{ml})$ in small culture dishes ( $250 \mathrm{ml})$; these larvae are large and often buoyant, and can easily be transferred individually with a wide-bore pipette. Similarly, for negatively buoyant larvae, water can be removed from the surface through a filter mesh as they swim close to the bottom of the dish. Water changes can be carried out twice a week and containers cleaned once a week as previously described for planktotrophs.

\section{Notes on ophiuroids that brood embryos}

998 Ophiuroids that brood embryos are often small-bodied hermaphroditic species that produce large eggs, retained in the ovaries after fertilization until an advance juvenile stage (Fig. 15; Byrne, 1991; Hendler, 1975, 1991). Embryos are brooded internally in the bursae at the base of the arms and the juveniles emerge through the bursal slit (Byrne, 1991; Hendler, 1975).

Some brooding ophiuroids are known to be matrotrophic (i.e., they support embryos with maternally derived extraembryonic nutrition) including Amphipholis squamata (Fig. 15C; Fell, 1946), Amphiura magellanica Ljungman (Mortensen, 1920), Ophiactis kroeyeri Lütken (Mortensen, 1920), 1006 Ophiophycis gracilis Mortensen (1933) and Ophionotus hexactis Smith (Mortensen, 1921). Few species are known to brood pelagic-type lecithotrophic larvae. A vitellaria larva that lacks ciliary bands has been reported in Ophionereis olivacea Clark (Byrne, 1991) and Ophiopeza spinosa has a 
swimming vitellaria larva (Fig. 15B; Byrne, Cisternas \& O'Hara, 2008).

1010

The embryos, larvae and early juveniles of southern tropical O. spinosa (Fig. 15 A,B; Byrne et al, 2008)

1012 and the cosmopolitan temperate and warm temperate brooder A. squamata (Fig. 15C; M.F.

Strathmann, 1987) can be dissected out of the bursae and transferred individually with a pipette to

1014 dishes (e.g., 6-well culture dishes) with $10 \mathrm{ml} \mathrm{FSW}$ or ASW. The aboral side of the parent's disc can be removed by cutting along its edge with scissors and severing the connective tissue that connects

1016 the disc to the skeletal elements above each arm. The bursae, which can be seen inter-radially and on both sides of the base of each of the arms, can gently be teased apart with fine forceps to reveal 1018 the embryos and juveniles (Fig. 15). FSW or ASW can be replaced every two days as indicated for other larval cultures until metamorphosis into juveniles is complete.

\section{Encapsulated embryos}

A number of ophiuroids have embryos that develop within capsules such as $O$. hexactis (Mortensen, 1921), Amphioplus abditus Verrill (Hendler, 1977) and Amphiodia occidentalis Lyman (Emlet, 2006). Of these, only the embryos of $A$. abditus have been cultured. After spawning, fertilized eggs can be 1026 transferred with pipettes to glass dishes at densities of 2-5 embryos per $\mathrm{ml}$ in $50 \mathrm{ml}$ of FSW or ASW. Water can easily be aspirated as the embryos are attached to the bottom of the dish via their fertilization envelopes. Water should be replaced every two days until development is completed (Hendler, 1977). 
Unlike other echinoderms, ophiuroid larvae appear to settle naturally and without the need for specific exogenous settlement cues (Allen \& Podolsky, 2007; Hendler, 1991; Selvakumaraswamy \& Byrne, 2006). They may be seen sinking to the bottom of the container, testing the surfaces with 1036 their juvenile podia. The larval arms appear to be released from the juvenile body in mid-water or upon attachment to a surface (Fig. 14D,E; Hendler, 1991; Selvakumaraswamy \& Byrne, 2006). Once

1038 the larvae have metamorphosed and settled, the developing juveniles are usually found attached to the sides or bottom of the container. Water can be gently decanted out and replaced once a week

1040 from here onwards as needed. Juveniles have been cultured for a short period of time (a few weeks) in these conditions (P. Selvakumaraswamy, pers. comm.).

For juveniles deriving from lecithotrophic (vitellaria) larvae, we have continued the larval culturing techniques for vitellaria outlined above with good success after settlement for $\sim 10 \mathrm{~d}$ and until the mouth opens.

\section{ACKNOWLEDGEMENTS}

We thank Richard Strathmann and Chris Lowe for advice and discussions. We dedicate this chapter 1052 to Dr. Susie Balser, who looked at the same larvae that many had before her, and yet saw things that nobody else had. 


\section{References Cited}

1058 Agudo, N. (2007). Sandfish hatchery techniques. Nouméa, New Caladonia: The WorldFish Center, Secretariat of the Pacific Community and Australian Centre for International Agricultural 1060 Research.

Allen, J. D., \& Podolsky, R. D. (2007). Uncommon diversity in developmental mode and larval form in the genus Macrophiothrix (Echinodermata: Ophiuroidea). Mar. Biol., 151, 85-97.

Allen, J. D. (2012). Effects of egg size reductions on development time and juvenile size in three species of echinoid echinoderms: Implications for life history theory. J. Exp. Mar. Biol. Ecol., 422$423,72-80$.

Amemiya, S., Hibino, T., Nakano, H., Yamaguchi, M., Kuraishi, R., \& Kiyomoto, M. (2015). Development of ciliary bands in larvae of the living isocrinid sea lily Metacrinus rotundus. Acta Zool., 96, 36-43.

1068 Aronowicz, J. (2007). The "agitator": an inexpensive device for culturing large numbers of fragile marine invertebrate larvae. Mar. Biol., 151, 1137-1141

1070 Balser, E. J. (1998). Cloning by ophiuroid echinoderm larvae. Biol. Bull., 194, 187-193.

Balser, E. J. (2002). Phylum Echinodermata: Crinoidea. In C. M. Young, M. A. Sewell \& M. E. Rice (Eds.), $1072 \quad$ Atlas of Marine Invertebrate Larvae (pp. 463-482). New York: Academic Press. 
Bashevkin, S. M., Lee, D., Driver, P., Carrington, E., \& George, S. B. (2016). Prior exposure to low salinity affects the vertical distribution of Pisaster ochraceus (Echinodermata: Asteroidea) larvae in haloclines. Mar. Ecol. Progr. Ser., 542, 123-140.

1076 Becker, P., Gillan, D., Lanterbecq, D., Jangoux, M., Rasolofonirina, R., Rakotovao, J., \& Eeckhaut, I. (2004). The skin ulceration disease in cultivated juveniles of Holothuria scabra (Holothuroidea, 1078 Echinodermata). Aquaculture, 242, 13-30.

Birkeland, C., Chia. F.-S., \& Strathmann, R. R. (1971). Development, substratum selection, delay of metamorphosis and growth in the seastar, Mediaster aequalis. Biol. Bull., 141, 99-108

Bishop, C. D., \& Brandhorst, B.P. (2007). Development of nitric oxide synthase-defined neurons in the sea urchin larval ciliary band and evidence for a chemosensory function during metamorphosis. Dev. Dyn., 236, 1535-1546.

1084 Brooks, W. K., \& Grave, C. (1899). Ophiura brevispina. Mem. Natn. Acad. Sci., 8, 79-100.

Burke, R. D. (1980). Development of pedicellariae in the pluteus larva of Lytechinus pictus 1086 (Echinodermata: Echinoidea). Can. J. Zool., 58, 1674-1682.

Burke, R. D. (1984). Pheromonal control of metamorphosis in the pacific sand dollar, Dendraster 1088 excentricus. Science, 225, 442-443.

Byrne, M. (1991). Reproduction, development and population biology of the Caribbean ophiuroid Ophionereis olivacea, a protandric hermaphrodite that broods its young. Mar. Biol., 111, 387-399.

Byrne M. (1995). Changes in larval morphology in the evolution of benthic development by Patiriella exigua (Asteroidea), a comparison with the larvae of Patiriella species with planktonic development. Biol. Bull., 188:,293-305. 
1094 Byrne, M. (1996). Viviparity and intragonadal cannibalism in the diminutive asterinid sea stars Patiriella vivipara and P. parvivipara. Mar. Biol., 125, 551-567.

1096

Byrne, M. (2005). Viviparity in the sea star Cryptasterina hystera (Asterinidae) - conserved and modified features in reproduction and development. Biol. Bull., 208, 81-91.

1098

Byrne, M., Cisternas, P., \& O'Hara, T. D. (2008). Brooding of pelagic-type larvae in Ophiopeza spinosa: reproduction and development in a tropical ophiodermatid brittle-star. Invert. Biol., 127, 98-107.

Byrne, M., Emlet, R., \& Cerra, A. (2001). Ciliated band structure in planktotrophic and lecithotrophic larvae of Heliocidaris species (Echinodermata:Echinoidea): conservation and change. Acta Zool., 82, 189-199.

Byrne, M., \& Selvakumaraswamy, P. (2002). Phylum Echinodermata: Ophiuroidea. In C. M. Young, M. A. Sewell \& M. E. Rice (Eds.), Atlas of Marine Invertebrate Larvae (pp. 483-498). New York: Academic Press.

1106 Cameron, R. A., Tosteson, T. R., \& Hensley, V. (1989). The control of sea urchin metamorphosis: ionic effects. Develop. Growth Differ., 31, 589-594.

1108 Carpizo-Ituarte, E., Salas-Garza, A. \& Parés-Sierra, G. (2002). Induction of metamorphosis with KCl in three species of sea sea urchins and its implications in the production of juveniles. Cienc. Mar., $1110 \quad 28,157-166$

Castilla-Gavilan, M., Buzin, F., Cognie, B., Dumay, J., Turpin, V., \& Decottignies, P. (2018). Optimising 1112 microalgae diets in sea urchin Paracentrotus lividus larviculture to promote aquaculture diversification. Aquaculture, 490, 251-259.

1114 Cavanaugh, G. M. (1975). Formulae and Methods VI. Woods Hole: The Marine Biological Laboratory. 
Chen, B.-Y., \& Chen, C.-P. (1992). Reproductive cycle, larval development, juvenile growth and 1116 population dynamics of Patiriella pseudoexigua (Echinodermata: Asteroidea) in Taiwan. Mar. Biol., 113, 271-280.

1118 Chia, F.-S. (1966). Development of a deep-sea cushion star, Pteraster tesselatus. Proc. Cal. Acad. Sci., $34,505-510$.

1120 Chia, F.-S., \& Burke, R. D. (1978). Echinoderm metamorphosis: fate of larval structures. In F. S. Chia \& M. E. Rice (Eds.), Settlement and Metamorphosis of Marine Invertebrate Larvae (pp. 219-234). New 1122 York: Elsevier.

Cisternas, P., \& Byrne, M. 2005. Larval development in the ophiuroid Ophiarachnella gorgonia 1124 (Ophiodermatidae): evidence for developmental heterochronies between species with Type I and Type II development. Can. J. Zool., 83, 1067-1079

1126 Derbès, A. (1847). Observations sur le mechanism et les phénomènes qui accompagnent la formation de l'embryon chez l'oursin comestible. Ann. de Sci. Nat. III S'er. Zool., 8, 80-98.

1128 Dupont, S., Ortega-Martínez, O., \& Thorndyke, M. 2010. Impact of near-future ocean acidification on echinoderms. Ecotoxicology, 19, 449-462.

1130 Eaves, A. A., \& Palmer, A. R. 2003. Reproduction - Widespread cloning in echinoderm larvae. Nature, $425,146-146$.

1132 Eeckhaut, I., Parmentier, E., Becker, P., Gomez Da Silva, S., \& Jangoux, M. 2004. Parasites and biotic diseases in field and cultivated sea cucumbers. In A. Lovatelli, C. Conand, S. Purcell, S. Uthicke, $1134 \quad$ J.-F. Hamel \& A. Mercier (Eds.), Advances in sea cucumber aquaculture and management (pp. 311 325). FAO Fisheries Technical Paper No. 463. Rome: FAO. 
1136 Elphick, M. R., \& Melarange, R. (2001). Neural control of muscle relaxation in echinoderms. J. Exp. Biol., 204, 875-885.

1138 Emlet, R. B. (2006). Direct development of the brittle star Amphiodia occidentalis (Ophiuroidea, Amphiuridae) from the northeastern Pacific Ocean. Invertebr. Biol., 125, 154-171.

1140 Emlet, R. B. (1988). Larval form and metamorphosis of a "primitive" sea urchin, Eucidaris thouarsi (Echinodermata, Echinoidea, Cidaroida), with implications for developmental and phylogenetic studies. Biol. Bull., 174, 4-19.

Emlet, R. B. (2010). Morphological evolution of newly metamorphosed sea urchins-a phylogenetic and functional analysis. Integr. Comp. Biol., 50, 571-588.

Fadl, A. E. A., Mahfouz, M. E., El-Gamal, M. M. T., \& Heyland, A. (2017). New biomarkers of postsettlement growth in the sea urchin Strongylocentrotus purpuratus. Heliyon, 3, e00412.

Fell, H. B. (1946.) The embryology of the viviparous ophiuroid Amphipholis squamata Delle Chiajie. Trans. R. Soc. N.Z., 75, 419-464.

Fenaux, L. (1969). Le developpement larvaire chez Ophioderma longicauda (Retzius). Cah. Biol. Mar., $10,59-62$.

Gaylord, B., Hodin, J., \& Ferner, M. C. (2013). Turbulent shear spurs settlement in larval sea urchins. Proc. Natl. Acad. Sci. USA, 110, 6901-6906.

George, S. B. (1994). Population differences in maternal size and offspring quality for Leptasterias epichlora (Brandt) (Echinodermata, Asteroidea). J. Exp. Mar. Biol. Ecol., 175, 121-131

Gianasi, B. L., Hamel, J.-F., \& Mercier, A. (2018a). Full allogeneic fusion of embryos in a holothuroid echinoderm. Proc. Roy. Soc. B. Biol. Sci., 285, 20180339. 
Gianasi, B. L., Hamel, J.-F., \& Mercier, A. (2018b). Morphometric and behavioural changes in the early 1158 life stages of the sea cucumber Cucumaria frondosa. Aquaculture, 490, 5-18.

Gladfelter, W. B. (1978). General ecology of the cassiduloid urchin Cassidulus caribbearum. Mar. Biol., $1160 \quad 47,149-160$.

Gosselin, P., \& Jangoux, M. (1998). From competent larva to exotrophic juvenile, a morphological 1162 study of the perimetamorphic period of Paracentrotus lividus (Echinodermata, Echinoida). Zoomorphology, 118, 31-43.

1164 Guillard, R. R. L. (1975). Culture of phytoplankton for feeding marine invertebrates. In W. L. Smith \& M. H. Chanley (Eds.), Culture of Marine Invertebrate Animals (pp. 26-60). New York: Plenum Press.

1166 Hadfield, M. G. (2011). Biofilms and marine invertebrate larvae: What bacteria produce that larvae use to choose settlement sites. Annu. Rev. Mar. Sci., 3, 453-470

1168 Hair, C., Pickering, T., Meo, S., Vereivalu, T., Hunter, J., Cavakiqali, L., Hamilton, R., Lokani, P., Tsiresy, G., \& Pascal, B. (2011). Sandfish culture in Fiji Islands. SPC Beche-de-mer Inf. Bull., 3-11.

1170 Hamel, J.-F., \& Mercier, A. (1996). Early development, settlement, growth, and spatial distribution of the sea cucumber Cucumaria frondosa (Echinodermata, Holothuroidea). Can. J. Fish. Aquat. Sci., $1172 \quad 53,253-271$.

Hamel, J.-F., Pawson, D. L., Conand, C., \& Mercier, A. (2001). The sea cucumber Holothuria scabra 1174 (Holothuroidea, Echinodermata), its biology and exploitation as beche-de-mer. Adv. Mar. Biol., $41,129-223$. 
1176 Hamel, J.-F., \& Mercier, A., (2008a). Population status, fisheries and trade of sea cucumbers in temperate areas of the northern hemisphere. In V. Toral-Granda, A. Lovatelli \& M. Vasconcellos (Eds.), Sea Cucumbers. A Global Review of Fisheries and Trade (pp. 257-292). FAO Fisheries and Aquaculture Technical paper 516. Rome: FAO.

1180 Hamel, J.-F., \& Mercier, A. (2008b). Precautionary management of Cucumaria frondosa in Newfoundland and Labrador, Canada. In V. Toral-Granda, A. Lovatelli \& M. Vasconcellos (Eds.), Sea Cucumbers. A Global Review of Fisheries and Trade (pp. 293-306). FAO Fisheries and Aquaculture Technical paper 516. Rome: FAO.

1184 Hart, M. W. (1991). Particle captures and the method of suspension feeding by echinoderm larvae. Biol. Bull., 180, 12-27.

1186 Hendler, G. (1975). Adaptational significance of the patterns of ophiuroid development. Am. Zool., $15,691-715$

1188 Hendler, G. (1977). Development of Amphioplus abditus (Verrill) (Echinodermata, Ophiuroidea), I. Larval biology. Biol. Bull., 152, 51-63.

1190 Hendler, G. (1991). Echinodermata, Ophiuroidea. In A. C. Giese, J. S. Pearse \& V. B. Pearse (Eds.), Reproduction of Marine invertebrates, (pp. 355-511). Pacific Grove: The Boxwood Press.

1192 Herrmann, K., Siefker, B., \& Berking, S. (2003). Sterile polystyrene culture dishes induce transformation of polyps into medusae in Aurelia aurita (Scyphozoa, Cnidaria) Methods Cell Sci., $25,135-136$.

Heyland, A., \& Hodin, J. (2004). Heterochronic developmental shift caused by thyroid hormone in 1196 larval sand dollars and its implications for phenotypic plasticity and the evolution of nonfeeding development. Evolution, 58, 524-538. 
1198

1200

1202

1204

1206

1208

1210

1212

1214

Heyland, A., \& Hodin, J. (2014). A detailed staging scheme for late larval development in Strongylocentrotus purpuratus focused on readily-visible juvenile structures within the rudiment. BMC Dev. Biol., 14, 22.

Heyland, A., Reitzel, A. M., \& Hodin, J. (2004). Thyroid hormones determine developmental mode in sand dollars (Echinodermata, Echinoidea). Evol. Dev., 6, 382-389.

Heyland, A., Price, D., Bodnarova-Buganova, M., \& Moroz, L. L. (2006a). Thyroid hormone metabolism and peroxidase function in two non-chordate animals. J. Exp. Zool (Mol. Dev. Evol.), 306B doi:10.1002/jez.b

Heyland, A., Reitzel, A. M., Price, D., \& Moroz, L. L. (2006b). Endogenous thyroid hormone synthesis in facultative planktotrophic larvae of the sand dollar Clypeaster rosaceus, implications for the evolutionary loss of larval feeding. Evol. Dev., 8, 568-579.

Highsmith, R. C. (1982). Induced settlement and metamorphosis of sand dollar (Dendraster excentnicus) larvae in predator-free sites, adult sand dollar beds. Ecology, 63, 329-337.

Highsmith, R. C., \& Emlet, R. B. (1986). Delayed metamorphosis, effect on growth and survival of juvenile sand dollars (Echinoidea, Clypeasteroida). Bull. Mar. Sci, 39, 347-361.

Hill, B. J., Berthe, F., Lightner, D. V., \& Sais, R. E. (2013). Methods for disinfection of aquaculture establishments. In Manual of Diagnostic Tests for Aquatic Animals (pp. 28-39). Paris: Office International des Epizooties.

1216 Ho, E. C., Buckley, K. M., Schrankel, C. S., Schuh, N. W., Hibino, T., Solek, C. M., Bae, K., Wang, G., \& Rast, J.P. (2016). Perturbation of gut bacteria induces a coordinated cellular immune response in the purple sea urchin larva. Immunol. Cell Biol., 94, 861-874. 
Hodin, J. (2006). Expanding networks, Signaling components in and a hypothesis for the evolution 1220 of metamorphosis. Integr. Comp. Biol., 46, 719-742.

Hodin, J., Ferner, M. C., Ng, G., Lowe, C. J., \& Gaylord, B. (2015). Rethinking competence in marine life cycles, ontogenetic changes in the settlement response of sand dollar larvae exposed to turbulence. R. Soc. Open Sci., 2, 150114.

1224 Hodin, J., Ferner, M. C., Ng, G., \& Gaylord, B. (2018). Turbulence exposure recapitulates desperate behavior in late-stage sand dollar larvae. BMC Zool., 3, 9.

1226 Holland, N. (1991). Echinodermata, Crinoidea. In A. C. Giese, J. S. Pearse \& V. B. Pearse (Eds.), Reproduction of Marine invertebrates, (pp. 247-299). Pacific Grove: The Boxwood Press.

1228 Hoekstra, L. A., Moroz, L. L., \& Heyland, A. (2012). Novel insights into the echinoderm nervous system from histaminergic and FMRFaminergic-like cells in the sea cucumber Leptosynapta clarki. PLoS $1230 \quad O N E, 7, \mathrm{e} 44220$.

Huggett, M. J., King, C. K., Williamson, J. E., \& Steinberg, P. D. (2005). Larval development and 1232 metamorphosis of the australian diadematid sea urchin Centrostephanus rodgersii. Invert. Reprod. Dev., 47, 197-204.

1234 Hurst, A. (1967). The egg masses and veligers of thirty northeast pacific Opistobranchs. Veliger, 9, 255-288.

1236 Israel, J. W., Martik, M. L., Byrne, M., Raff, E. C., Raff, R. A., McClay, D. R., \& Wray, G. A. (2016). Comparative developmental transcriptomics reveals rewiring of a highly conserved gene 1238 regulatory network during a major life history switch in the sea urchin genus Heliocidaris. PLoS Biol., 14, e1002391. 
1240 Kacenas, S. E., \& Podolsky, R. D. 2018. Density-dependent expression of plasticity in larval morphology, effects of actual and apparent competitors. Mar. Ecol. Prog. Ser., 593, 1-13.

1242 Kamya, P. Z., Dworjanyn, S. A., Hardy, N., Mos, B., Uthicke, S., \& Byrne, M. (2014). Larvae of the coral eating crown-of-thorns starfish, Acanthaster planci in a warmer-high $\mathrm{CO}_{2}$ ocean. Global Ch. Biol.,

$1244 \quad 20,3365-3376$.

Kitazawa, C., Kobayashi, C., Kasahara, M., Takuwa, Y., \& Yamanaka, A. (2012). Morphogenesis of adult 1246 traits during the early development of Mespilia globulus Linnaeus, 1758 (Echinodermata, Echinoidea). Zool. Stud., 51, 1481-1489.

1248 Kumé, M., \& Dan, K. (1968). Invertebrate Embryology. Belgrade: Nolit Publishing House.

Lawrence, J.M, (Ed.). (2013). Sea Urchins, Biology and Ecology (Third Edition). Developments in $1250 \quad$ Aquaculture and Fisheries Science, vol. 38. Oxford: Elsevier.

Leahy, P. S. (1986). Laboratory culture of Strongylocentrotus purpuratus adults, embryos, and larvae. In T. E. Scroeder (Ed.), Echinoderm Gametes and Embryos. Methods in Cell Biology, 27(C), 1-13.

Leong, P., \& Manahan, D. (1997). Metabolic importance of Na+/K+-atpase activity during sea urchin 1254 development. J. Exp. Biol., 200, 2881-2892.

Lizárraga, D., Danihel, A., \& Pernet, P. (2017). Low concentrations of large inedible particles reduce $1256 \quad$ feeding rates of echinoderm larvae. Mar. Biol., 164, 102.

Marsh, A. G., Maxson, R. E., \& Manahan, D. T. (2001). High macromolecular synthesis with low 1258 metabolic cost in Antarctic sea urchin embryos. Science, 291, 1950-1952.

Martinez A. S., Byrne M., \& Coleman, R. A. (2017). Filling in the grazing puzzle, A synthesis of 1260 herbivory in starfish. Oceanogr. Mar. Biol. Ann. Rev., 55, 1-34 
McAlister, J. S., \& Miner, B. G. (2018). Phenotypic plasticity of feeding structures in marine invertebrate larvae. In T. J. Carrier, A. M. Reitzel \& A. Heyland (Eds.), Evolutionary Ecology of Marine Invertebrate Larvae (pp. 103-123). New York: Oxford University Press.

1264 McDonald, K. A., \& Vaughn, D. (2010). Abrupt change in food environment induces cloning in plutei of Dendraster excentricus. Biol. Bull., 219, 38-49.

1266 McEdward, L. R., \& Janies, D. A. (1993). Life cycle evolution in Asteroids, What is a larva? Biol. Bull., $184,255-268$.

1268 McEdward, L. R., \& Miner, B. G. (2001). Larval and life-cycle patterns in echinoderms. Can. J. Zool., 79, 1125-1170.

Mercier, A., \& Hamel, J.-F. (2013). Sea cucumber aquaculture, hatchery production, juvenile growth and industry challenges. In G. Allan \& G. Burnell (Eds.) Advances in Aquaculture Hatchery Technology (pp. 431-454). Cambridge: Woodhead Publishing Ltd.

Mercier, A., Ycaza, R. H., \& Hamel, J.-F. (2004). Aquaculture of the Galapagos sea cucumber, Isostichopus fuscus. In A. Lovatelli, C. Conand, S. Purcell, S. Uthicke, J.-F. Hamel \& A. Mercier (Eds.), Advances in sea cucumber aquaculture and management (pp. 347-358). FAO Fisheries Technical Paper No. 463. Rome: FAO.

Mercier, A., Ycaza, R. H., Espinoza, R., Haro, V. M. A., \& Hamel, J.-F. (2012). Hatchery experience and useful lessons from Isostichopus fuscus in Ecuador and Mexico. In C. A. Hair, T. D. Pickering \& D. J. Mills (Eds.), Asia-Pacific Tropical Sea Cucumber Aquaculture Symposium, ACIAR Proceedings (pp. 79-90). Canberra: Australian Centre for International Agricultural Research. 
Miller, B. A., \& Emlet, R. B. (1999). Development of newly metamorphosed juvenile sea urchins

1282 (Strongylocentrotus franciscanus and S. purpuratus), morphology, the effects of temperature and larval food ration, and a method for determining age. J. Exp. Mar. Biol. Ecol., 235, 67-90.

1284 Milonas, L., Pernet, B., \& Bingham, B. L. (2010). Light influences feeding and growth of echinoplutei. Mar. Ecol. Progr. Ser., 404, 69-78.

1286 Mladenov, P. V. (1979). Unusual lecithotrophic development of the Caribbean brittle star Ophiothrix oerstedi. Mar. Biol., 55, 55-62.

1288 Mladenov, P. V. (1985). Development and metamorphosis of the brittle star Ophiocoma pumila, evolutionary and ecological implications. Biol. Bull., 168, 285-295.

1290 Montgomery, E. M., Hamel, J.-F., \& Mercier, A. (2017). Ontogenetic shifts in swimming capacity of echinoderm propagules, a comparison of species with planktotrophic and lecithotrophic larvae. 1292 Mar. Biol., 164, 43.

Montgomery E. M., Hamel J.-F., \& Mercier, A. (2018). Ontogenetic variation in photosensitivity of 1294 developing echinoderm propagules. J. Exp. Mar. Biol. Ecol., 500, 63-72.

Mortensen, T. (1920). On hermaphroditism in viviparous ophiuroids. Acta Zool., 1-18.

1296 Mortenson, T. (1921). Studies of the development and larval forms of Echinoderms. Copenhagen: G.E.C. Gad.

1298 Mortenson, T. (1931). Contributions to the study of the development and larval forms of Echinoderms I-II. Kgl. Danske Vidensk. Selsk. Skrifter, Naturv. Math. Afd. Række 9, 4(1), 1-39. 
1300

1302

Mortenson, T. (1937). Contributions to the study of the development and larval forms of

1304

Mortenson, T. (1938). Contributions to the study of the development and larval forms of

1306

Müller, J. (1846). Über die larven und die metamorphose der ophiuren und seeigel. Abh. König. Akad.

1308

Pearse, J.S., \& Cameron, R.A. (1991). Echinodermata, Echinoidea. In A. C. Giese, J. S. Pearse \& V. B.

1310 Pearse (Eds.), Reproduction of Marine invertebrates, (pp. 514-662). Pacific Grove: The Boxwood Press.

1312 Podolsky, R. D. \& McAlister, J. S. (2005). Developmental plasticity in Macrophiothrix brittlestars, are morphologically convergent larvae also convergently plastic? Biol. Bull., 209, 127-138.

1314 Purcell, S. W., Mercier, A., Conand, C., Hamel, J.-F., Toral-Granda, V., Lovatelli, A., \& Uthicke, S. (2013). Sea cucumber fisheries, global analysis of stocks, management measures and drivers of overfishing. Fish and Fisheries, 14, 34-59

Purcell, S. W., Polidoro, B. A., Hamel, J.-F., Gamboa, R. U., \& Mercier, A. (2014). The cost of being Roy. Soc. $B, 9$, e95075. 
1320 Purcell, S. W., Conand, C., Uthicke, S., \& Byrne, M. (2016). Ecological roles of exploited sea cucumbers. Oceanogr. Mar. Biol. Ann. Rev., 54, 367-386.

1322 Qiu, T., Zhang, T., Hamel, J.-F., \& Mercier, A. (2015). Development, settlement and post-settlement growth. In H. Yang, J.-F. Hamel \& A. Mercier (Eds), The Sea Cucumber Apostichopus japonicus, History, Biology and Aquaculture (pp. 111-132). London: Academic Press.

Ren, Y., Liu, W., Dong, S., \& Pearce, C. M. (2016). Effects of mono-species and bi-species microalgal diets on the growth, survival and metamorphosis of auricularia larvae of the California sea cucumber, Parastichopus californicus (Stimpson, 1857). Aquacult. Nutr., 22, 304-314.

1328 Roman, M. R., Holliday, D. V., \& Sanford, L. P. (2001). Temporal and spatial patterns of zooplankton in the Chesapeake Bay turbidity maximum. Mar. Ecol. Prog. Ser., 213, 215-227.

1330 Salas-Garza, A., Carpizo-Ituarte, E., Parés-Sierra, G., Martínez-López, R., \& Quintana-Rodríguez, R. (2005). Producción de juveniles de erizo rojo Strongylocentrotus franciscanus (Echinodermata, 1332 Echinoidea) en Baja California, México. Rev. Biol. Trop., 53 (Suppl. 3), 345-355.

Scholtz, R., Bolton, J. J., Macey, B. M. (2013). Effects of different microalgal feeds and their influence on larval development in the white-spined sea urchin Tripneustes gratilla. Afric. J. Mar. Sci., 35, 25-34.

1336 Selvakumaraswamy, P., \& Byrne, M. (2006). Evolution of larval form in ophiuroids, insights from the metamorphic phenotype of Ophiothrix (Echinodermata, Ophiuroidea). Evol. Dev., 8, 183-190.

1338 Selvakumaraswamy, P., \& Byrne, M. (2000). Reproduction, spawning and development in 5 ophiuroids from Australia and New Zealand. Invert. Biol., 119, 394-402.

1340 Smith, A. B. (1997). Echinoderm Larvae and Phylogeny. Ann. Rev. Ecol. Syst., 28, 219-241. 
Smith, M. M., Smith, L. C., Cameron, R. A, \& Urry, L. A. (2008). The larval stages of the sea urchin, 1342 Strongylocentrotus purpuratus. J. Morph., 269, 713-733.

Soars, N. A., Prowse, T. A. A., \& Byrne, M. (2009). Overview of phenotypic plasticity in echinoid larvae, 'Echinopluteus transversus' type vs. typical echinoplutei. Mar. Ecol. Prog. Ser., 383, 113-125.

Stancyk, S. E. (1973). Development of Ophiolepis elegans (Echinodermata, Ophiuroidea) and its implications in the estuarine environment. Mar. Biol., 21, 7-12.

Strathmann, M. F. (1987). Reproduction and Development of Marine Invertebrates of the Northern Pacific Coast, Data and Methods for the Study of Eggs, Embryos and Larvae. Seattle: University of Washington Press.

Strathmann, R. R. (1971). The feeding behavior of planktotrophic echinoderm larvae, mechanisms, regulation, and rates of suspension feeding. J. Exp. Mar. Biol. Ecol., 6, 109-160.

1352 Strathmann, R. R. (1978). Larval settlement in echinoderms. In F. S. Chia \& M. E. Rice (Eds.), Settlement and Metamorphosis of Marine Invertebrate Larvae (pp. 235-246). New York: Elsevier.

1354 Strathmann, R. R. (1987). Larval feeding. In A. C. Giese, J. S. Pearse \& V. B. Pearse (Eds.), Reproduction of Marine invertebrates, (pp. 465-550). Pacific Grove: The Boxwood Press.

1356 Strathmann, R. R. (2014). Culturing larvae of marine invertebrates. In D.J. Carroll \& S.A. Stricker (Eds.), Developmental Biology of the Sea Urchin and Other Marine Invertebrates, Methods and Protocols. Methods in Molecular Biology, 1128, 1-25.

Strathmann, R. R., \& Grünbaum, D. (2006). Good eaters, poor swimmers, compromises in larval form. Integr. Comp. Biol., 46, 312-322. 
Strathmann, R. R., Fenaux, L., \& Strathmann, M. F. (1992). Heterochronic developmental plasticity in larval sea urchins and its implications for the evolution of nonfeeding larvae. Evolution, 46, 972986.

1364 Strickland, S., von Dassow, G., Ellenberg, J., Foe, V., Lenart, P., \& Burgess, D. (2004). Light microscopy of echinoderm embryos. Methods Cell Biol., 74, 371-409.

1366 Suckling, C. C., Terrey, D, \& Davies, A. J. (2018). Optimising stocking density for the commercial cultivation of sea urchin larvae. Aquaculture, 488, 96-104.

1368 Sui, X., (1990). Seed production and cultivation of sea cucumber. Agriculture Press of China, 107-153.

Sutherby, J., Giardini, J. L., Nguyen, J., Wessel, G., Leguia, M., \& Heyland, A. (2012). Histamine is a modulator of metamorphic competence in Strongylocentrotus purpuratus (Echinodermata, Echinoidea). BMC Dev. Biol., 12, 14.

1372 Swanson, R. L., Byrne, M., Prowse, T. A. A., Mos, B., Dworjanyn, S. A., \& Steinberg, P. D. (2012). Dissolved histamine, a potential habitat marker promoting settlement and metamorphosis in sea urchin larvae. Mar. Biol., 159, 915-925.

Toral-Granda, V., Lovatelli, A., \& Vasconcellos, M. 2008. Sea cucumbers, A global review of fisheries and trade. FAO Fisheries and Aquaculture Technical Paper 516. Rome: FAO.

Turner, R. D. 1976. Fixation and preservation of molluscan zooplankton. In H.F. Steedman (Ed.), Zooplankton Fixation and Preservation (pp. 290-300). Paris: UNESCO Press.

Vellutini, B. C., \& Migotto, A. E. 2010. Embryonic, larval, and juvenile development of the sea biscuit Clypeaster subdepressus (Echinodermata, Clypeasteroida). PLoS ONE, 5, e9654. 
Wheeler, J. D., Chan, K. Y. K., Anderson, E. J., \& Mullineaux, L. S. (2016). Ontogenetic changes in larval swimming and orientation of pre-competent sea urchin Arbacia punctulata in turbulence. J. Exp. Biol., 219, 1303-1310.

1384 Wolfe. K., Graba-Landry, A., Dworjanyn S. A., \& Byrne, M. (2017). Superstars, assessing nutrient thresholds for enhanced larval success of Acanthaster planci, a review of the evidence. Mar. Pollut. Bull., 116, 307-314.

Wray, G.A. (1992). The evolution of larval morphology during the Post-Paleozoid radiation of 1388 echinoids. Paleobiol., 18, 258-287.

Wray G. A. (1996). Parallel evoluton of nonfeeding larvae in echinoids, Syst. Biol., 45, 308-22.

Wray, G. A., \& Bely, A. E. (1994). Several distinct factors drive the evolution of early development in echinoderms. Development (Suppl.), 97-106.

Wray, G. A., \& Raff, R. A. (1989). Evolutionary modification of cell lineage in the direct developing sea urchin Heliocidaris erythrogramma. Dev. Biol., 132, 458-447.

1394 Wray, G. A., \& Raff, R. A. (1991). The evolution of developmental strategy in marine invertebrates. Trends Ecol. Evol., 6, 45-50

1396 Xing, R-I., Wang, C-h., Cao X-b., \& Chang, Y-q. (2007). The potential value of different species of benthic diatoms as food for newly metamorphosed sea urchin Strongylocentrotus intermedius. $1398 \quad$ Aquaculture, 263, 142-149.

Yamashita, M. (1985). Embryonic development of the brittle-star Amphipholis kochii in laboratory $1400 \quad$ culture. Biol. Bull., 169, 131-142. 
Yang, H., Hamel, J.-F., \& Mercier, A. (2015). The sea cucumber Apostichopus japonicus, history, biology and aquaculture. London: Academic Press.

Zhang L., Song X., Hamel J.-F., \& Mercier, A. (2015). Aquaculture, stock enhancement, and restocking. In H. Yang, J.-F. Hamel \& A. Mercier (Eds), The Sea Cucumber Apostichopus japonicus, History, Biology and Aquaculture (pp. 289-322). London: Academic Press.

1406 Zhang, X., Sun, L., Yuan, J., Sun, Y., Gao, Y., Zhang, L., Li, S., Dai, H, Hamel, J.-F., Liu, C., Yu, Y., Liu, S., Lin, W., Guo, K., Jin, S., Xu, P., Storey, K. B., Huan, P., Zhang, T., Zhou, Y., Zhang, J., Lin, C., Li, X., Xing, L., Huo, D., Sun, M., Wang, L., Mercier, A., Li, F., Yang, H., \& Xiang, J. (2017). The sea cucumber genome provides insights into morphological evolution and visceral regeneration.

$1410 \quad$ PLoS Biol., 15(10), e2003790. 


\section{TABLES}

\begin{tabular}{|c|c|c|}
\hline $\begin{array}{l}\text { Order: Family } \\
\text { Species }\end{array}$ & $\begin{array}{l}\mathrm{KCl} \text { concen- } \\
\text { tration }\end{array}$ & References \\
\hline \multicolumn{3}{|l|}{ Clypeasteroida: Clypeasteridae } \\
\hline Clypeaster rosaceus Linnaeus & $80 \mathrm{mM}$ & Heyland, Reitzel, Price \& Moroz, 2006b \\
\hline \multicolumn{3}{|l|}{ Clypeasteroida: Dendrasteridae } \\
\hline Dendraster excentricus Eschscholtz & $40 \mathrm{mM}$ & Heyland \& Hodin 2004, Hodin et al, 2015 \\
\hline \multicolumn{3}{|l|}{ Clypeasteroida: Mellitidae } \\
\hline Leodia sexiesperforata Leske & $40 \mathrm{mM}$ & Heyland Reitzel \& Hodin, 2004 \\
\hline Mellita tenuis Clark & $40 \mathrm{mM}$ & Heyland et al, 2004 \\
\hline \multicolumn{3}{|l|}{ Diadematoida: Diadematidae } \\
\hline Diadema antillarum Philippi & $40 \mathrm{mM}$ & A.H and J.H unpublished* \\
\hline \multicolumn{3}{|l|}{ Echinoida: Echinometridae } \\
\hline Colobocentrotus atratus Linnaeus & $120 \mathrm{mM}$ & J.H. unpublished \\
\hline Echinometra lucunter Linnaeus & $70 \mathrm{mM}$ & J.H. unpublished \\
\hline Echinometra viridis Agassiz & $70 \mathrm{mM}$ & J.H. unpublished \\
\hline Heterocentrotus mammillatus Linnaeus & $120 \mathrm{mM}$ & J.H. unpublished \\
\hline \multicolumn{3}{|l|}{ Echinoida: Strongylocentrotidae } \\
\hline Mesocentrotus franciscanus Agassiz & $100 \mathrm{mM}$ & $\begin{array}{l}\text { Carpizo-Ituarte, Salas-Garza \& Parés-Sierra, } \\
\text { 2002; Salas-Garza, Carpizo-Ituarte, Parés- } \\
\text { Sierra, Martínez-López \& Quintana- } \\
\text { Rodríguez, } 2005\end{array}$ \\
\hline Strongylocentrotus droebachiensis Müller & $70 \mathrm{mM}$ & J.H. unpublished \\
\hline Strongylocentrotus fragilis Jackson & $100 \mathrm{mM}$ & J.H. unpublished \\
\hline Strongylocentrotus pallidus Sars & $70 \mathrm{mM}$ & J.H. unpublished \\
\hline Strongylocentrotus purpuratus Stimpson & $70 \mathrm{mM}$ & Gaylord, Hodin \& Ferner, 2013 \\
\hline \multicolumn{3}{|l|}{ Echinoida: Toxopneustidae } \\
\hline Lytechinus pictus Verrill & $40 \mathrm{mM}$ & Cameron Tosteson \& Hensley, 1989 \\
\hline Lytechinus variegatus Lamarck & $40 \mathrm{mM}$ & $\begin{array}{l}\text { Heyland, Price, Bodnarova-Buganova \& } \\
\text { Moroz, 2006a }\end{array}$ \\
\hline
\end{tabular}




\section{Table 1. Minimum effective $\mathrm{KCl}$ concentrations for induction of settlement (complete}

1422 transformation from larva to juvenile) with a $1 \mathrm{~h}$ exposure in various echinoids. Note that these concentrations are the excess potassium added to SW (which already contains potassium at

1424 approximately $90 \mathrm{mM}$ ). Our experience is that there are significant differences among species in the rate at which they show signs of settlement following $\mathrm{KCl}$ exposure, from minutes (e.g., $D$.

1426 excentricus) to $12 \mathrm{~h}$ (e.g., in some S. fragilis larvae; note that ' $12 \mathrm{~h}$ ' here is $1 \mathrm{~h}$ of exposure and $11 \mathrm{~h}$ of recovery). Asterisks refer to limited data - in such cases, a higher concentration than the one listed 1428 could be more effective.

\section{FIGURE LEGENDS}

Fig. 1. Small scale culturing methods. A) Simple and effective reverse filtration apparatus. A small

1436 hole is cut in the bottom of a $50-\mathrm{ml}$ centrifuge tube, and plastic air tubing is inserted in the hole. The opening of the tube is covered with an appropriate-sized Nitex mesh. Here a commercially1438 available Nitex filter basket is shown which snaps in place in the 50-ml tube opening; note that not all 50-ml tubes fit these caps snugly. B) Simultaneous reverse filtration of multiple gallon jars with

1440 reverse filtration apparatuses akin to those shown in (A).C) Mechanical stirring rack in place with gallon jars and paddles. Photos by P. Kitaeff (A) and S. George (B,C). 


\section{Fig. 2. Forward filtration set-up as an alternative water change method for small scale}

1444 culturing. First, clean SW is poured into the filter basket to cover the filter mesh. Then, as pictured, the culture is gently poured into the filter basket, allowing the water to fill (and spill over the sides of) the small glass bowl and into the larger retention bowl. The small glass bowl and filter basket can then be moved directly to a dissection microscope to observe the concentrated larvae. The filter

1448 basket is then lifted out of the small glass bowl, inverted over a clean culture vessel containing clean sea water, and rinsed into that vessel with clean SW. The components of this system are shown in the inset. Note that, when assembled, the small glass bowl sits atop the large Petri dish shown in the inset at left so that the rim of the small glass bowl is above the rim of the larger retention bowl.

1452 Photos by B. Pernet.

1454 Fig. 3. An example medium scale larval culturing set-up. Larvae and food are kept in suspension in this 75-L cylindrical tank by gentle aeration. For water changes, the valve at the bottom drains the 1456 tank; larvae are retained on a Nitex mesh by a forward filtration method similar to that pictured in Fig. 2 but at a larger scale. To maintain the larvae below ambient temperatures in this set-up, the tank is kept within a temperature controlled, insulated cabinet. Photo by C. Lowe.

1460 Fig. 4. An example large scale culturing set up. A) Interior of climate controlled larval rearing room. The black cylinders are $200-\mathrm{L}$ cone bottom larval rearing tanks where larvae and

1462 phytoplankton are suspended with gentle aeration. B) Banjo screens are used for daily water exchanges by reverse filtration; this is a larger version of the reverse filtration apparatus shown in

1464 Fig 1A. C) When larvae need to be moved, or if the tanks are in need of thorough cleaning, forward filtration is carried out with a screened bucket and tote system. The principle is the same as the set- 
up shown in Fig. 2, but at a larger scale. Photos by D.L. Cohen.

Fig. 5. Asteroid planktotrophic larval development through metamorphosis, as exemplified by the NE Pacific ochre sea star Pisaster ochraceus Brandt at approximately $14^{\circ} \mathrm{C}$. A) Early bipinnaria

1470 stage larva. B) Early brachiolaria stage larva. C) Advanced brachiolaria. Note the juvenile rudiment with 5-fold symmetry apparent (white arrowhead), as well as closeups of the juvenile skeleton (upper 1472 inset) and brachiolar arms (lower inset). N.b., the inset photos are from different larvae than the one pictured in the main panel in (C). D) Juvenile. Scale bars: (A)-200 $\mu \mathrm{m} ;(B)-400 \mu \mathrm{m} ;(C)-1000 \mu \mathrm{m}$; (D)$1474300 \mu \mathrm{m}$. Main panel photos by S. George; inset photos in (C) by J. Hodin.

Fig. 6. Asteroid benthic larval development through metamorphosis in the six-armed brooding sea star Leptasterias hexactis Stimpson, from the NE Pacific. Dissected oocytes will mature with 1methyladenine by standard methods (See Chapter 1 in this volume); embryos can thus be cultured in vitro apart from the mother through the juvenile stage (see Hodin, 2006). A) 2-cell stage. B) Modified non-feeding brachiolaria larva. C) Brachiolaria larva undergoing metamorphosis, oral view, with podia forming (arrowhead) along each ambulacrum (arm) in the juvenile portion of the larva 1482 (lower left). At this stage, the primordia of 5 of the 6 juvenile arms are well-formed-with 3 pairs of podia each. The primordium of the 6 th arm is the last to form, here with only one pair of podia just visible (white arrows). D) Aboral view of 6-armed juvenile, with spines and tube feet visible. Scale bars: (A)-260 $\mu \mathrm{m} ;(B)-100 \mu m ;(C, D)-120 \mu m$. Photos by J. Hodin.

Fig. 7. Asteroid settlement on coralline algae (Amphiroa sp.), in the six armed cushion star 1488 Meridiastra gunnii Gray, from subtropical and temperate Australian waters. (A) Several settled $M$. 
gunnii larvae and juveniles (orange) on an Amphiroa frond. (B) Close-up of a single settled M. gunnii

1490 larva. Scale bars: approx. 1 mm. Photos by M. Byrne.

1492 Fig. 8. Larval diversity in echinoids. A) 10-arm feeding pluteus of the NW Atlantic purple-spined sea urchin Arbacia punctulata Lamarck (Arbaciidae), pieced together from two photographs. B) 8-

1494 arm feeding pluteus of the NE Pacific purple sea urchin, Strongylocentrotus purpuratus Stimpson (Strongylocentrotidae). C) Advanced 8-arm pluteus of the NE Pacific sand dollar, Dendraster 1496 excentricus Eschscholtz (Clypeasteridae). Well-developed adult spines (arrowhead) and other juvenile structures are visible in the large rudiment of this competent larva. D) 8-arm feeding 1498 pluteus of the tropical E Pacific urchin Echinometra vanbrunti Aggasiz (Echinometridae). E,F) Larvae from two sister species of Australian urchins from the genus Heliocidaris (Echinometridae) with 1500 radically different developmental modes. E) 8-arm feeding pluteus of $H$. tuberculata Lamarck. F) Non-feeding (lecithotrophic) larva of H. erythrogramma Valenciennes; juvenile rudiment clearly visible (one of the five primary podia indicated with white arrowhead). G) Feeding pluteus larva, resulting from a hybrid cross between two Indian Ocean long-spined urchins (Diadematidae):

1504 Diadema savignyi Audouin (male) and Diadema setosum Leske (female). Effectively, this advanced larva has only one pair of enormous arms remaining; the three other arm pairs formed transiently earlier in ontogeny. Scale bars: $(A, D, E)-65 \mu m ;(B)-90 \mu m ;(C)-110 \mu m ;(F)-60 \mu m ;(G)-190 \mu m$. Photos by J. Hodin (A-C), J. McAlister (D), R. Emlet (E), P. Cisternas (F) and S. Dautov (G). E reproduced 1508 by permission from Byrne et al (2001). 
1512 Fig. 9. Echinoid benthic larval development through metamorphosis in the brooding lamp urchin, Cassidulis caribaearum Lamarck (Cassidulidae), from the Eastern Caribbean. A) Larval brood

1514 among the oral spines of the mother. B) 8-cell stage. C) Non-feeding reduced pluteus larva (at approximately the same stage as the brooded larvae in A). D) Post-metamorphic juvenile, at which

1516 point the offspring crawl away from the mother. Scale bars: (A)-500 $\mu \mathrm{m}$; (B)- $70 \mu \mathrm{m} ;(C)-120 \mu \mathrm{m}$; (D)$200 \mu \mathrm{m}$. Photos by J. Hodin.

Fig. 10. Holothuroid adults and larvae of two commonly-cultured species. A) Adult of the brown sea cucumber, Isostichopus fuscus Ludwig, an endangered species from the Tropical Pacific and Latin America. B) Auricularia larva of I. fuscus. C) Adult of the orange-footed sea cucumber,

1522 Cucumaria frondosa Gunnerus, from the North Atlantic. D) Pentactula larva of C. frondosa. Scale bars:

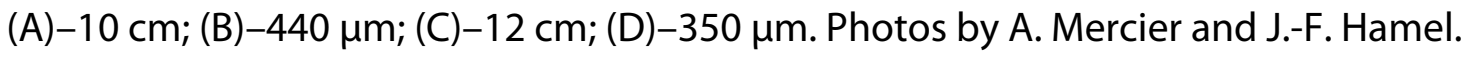

Fig. 11. Holothuroid planktotrophic larval development through metamorphosis in I. fuscus. A)

1526 Fully developed auricularia larva. B) Doliolaria larva. C) Pentactula undergoing settlement. D) Newly settled juvenile. Scale bars: $200 \mu \mathrm{m}$. Photos by A. Mercier and J.-F. Hamel.

Fig. 12. Main larval types in ophiuroids. Fully developed planktotrophic ophioplutei of A)

1530 Ophiactis resiliens Lyman from Oceania and B) the spiny brittle star Ophiothrix spiculata Le Conte from the Eastern Pacific. C) Lecithotrophic ophiopluteus of Macrophiothrix caenosa Hoggett from 1532 Western Australia. D) Vitellaria larva of Clarkcoma canaliculata Lütken from Oceania. Scale bars: 100 $\mu \mathrm{m}$. Photos by P. Cisternas (A, B, D) and J.D. Allen (C). 
Fig. 13. Developmental patterns of ophiuroids with larval development (Type I and Type II)

1536 classified according to mode of larval feeding (planktotrophy versus lecithotrophy) and larval form during metamorphosis.

1538

Fig. 14. Ophiuroid planktotrophic development though metamorphosis and post-settlement

cloning in the daisy brittle star, Ophiopholis aculeata Lyman, a species with circumpolar distribution in the North. A) Initiation of 5-fold symmetry in the rudiment; at this stage, the primordia of the 5

1542 arms (one indicated with arrow) are visible on the left side. B) Disintegration of the larval arms as the larva nears the settlement stage. C) Settled juvenile. D) Cloning via discarded pair of posterolateral

1544 arms. E) Still image from a video showing discarded posterolateral arms swimming away from a justsettled juvenile. Scale bars: $100 \mu \mathrm{m}$. Photos by J. Hodin.

Fig. 15. Brooding ophiuroids. A,B) Ophiopeza spinosa Ljungman. A) The disc and some of the 1548 digestive system has been removed to show developing offspring inside the bursae (arrows). B) Vitellaria larval stage from brood clutch in O. spinosa. C) Developing embryo of Amphipholis

1550 squamata Delle Chiaje partially attached to the bursal wall. Scale bars: (A) $-600 \mu \mathrm{m}$; (B)-300 $\mu \mathrm{m}$; (C)$100 \mu \mathrm{m}$. Photos by M. Byrne (A, B) and P. Cisternas (C). B reproduced by permission from Byrne et al 1552 (2008). 


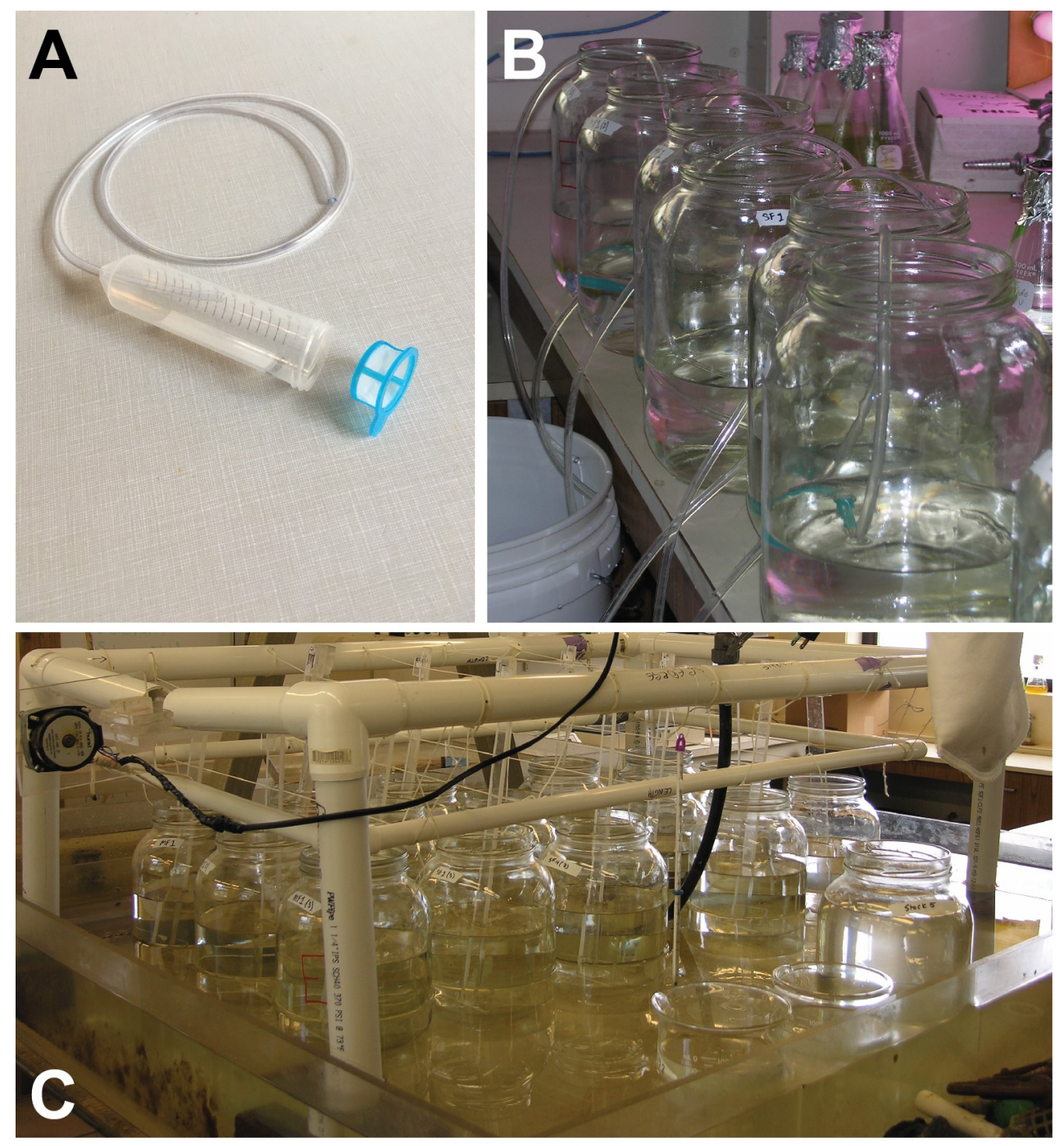

Fig. 1. Small scale culturing methods. A) Simple and effective reverse filtration apparatus. A small hole is cut in the bottom of a $50-\mathrm{ml}$ centrifuge tube, and plastic air tubing is inserted in the hole. The opening of the tube is covered with an appropriate-sized Nitex mesh. Here a commerciallyavailable Nitex filter basket is shown which snaps in place in the 50-ml tube opening; note that not all 50-ml tubes fit these caps snugly. B) Simultaneous reverse filtration of multiple gallon jars using reverse filtration apparatuses akin to those shown in (A).C) Mechanical stirring rack in place with gallon jars and paddles. Photos by P. Kitaeff (A) and S. George (B,C). 


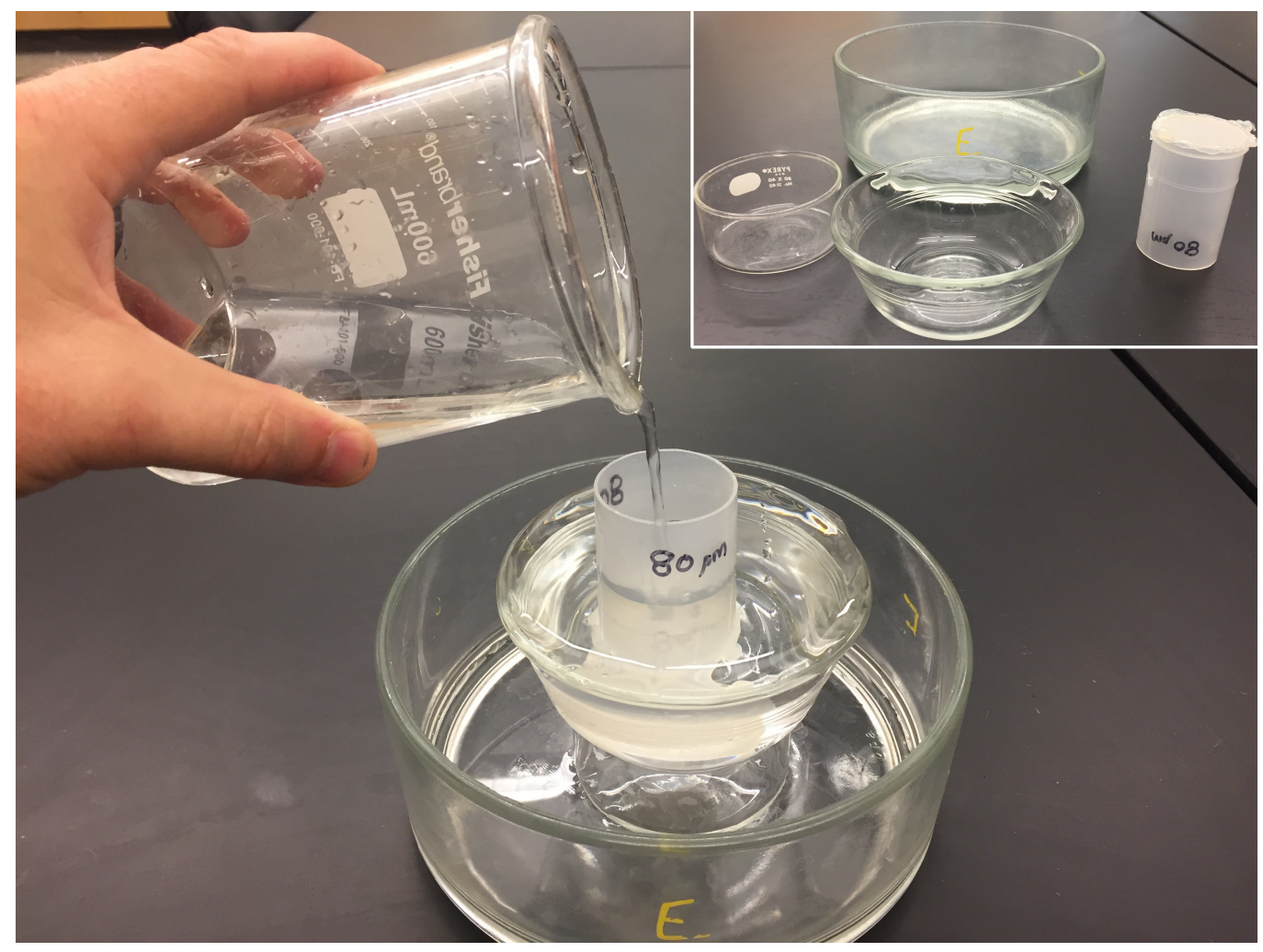

Fig. 2. Forward filtration set-up as an alternative water change method for small scale culturing. First, clean seawater is poured into the filter basket to cover the filter mesh. Then, as pictured, the culture is gently poured into the filter basket, allowing the water to fill (and spill over the sides of the finger bowl and into the larger retention bowl. The finger bowl and filter basket can then be moved directly to a dissection microscope to observe the concentrated larvae. The filter basket is then lifted out of the finger bowl, inverted over a clean culture vessel containing clean sea water, and rinsed into that vessel with clean seawater. The components of this system are shown in the inset. Note that, when assembled, the finger bowl sits atop the large Petri dish shown in the inset at left so that the rim of the finger bowl is above the rim of the larger retention bowl. Photos by B. Pernet. 


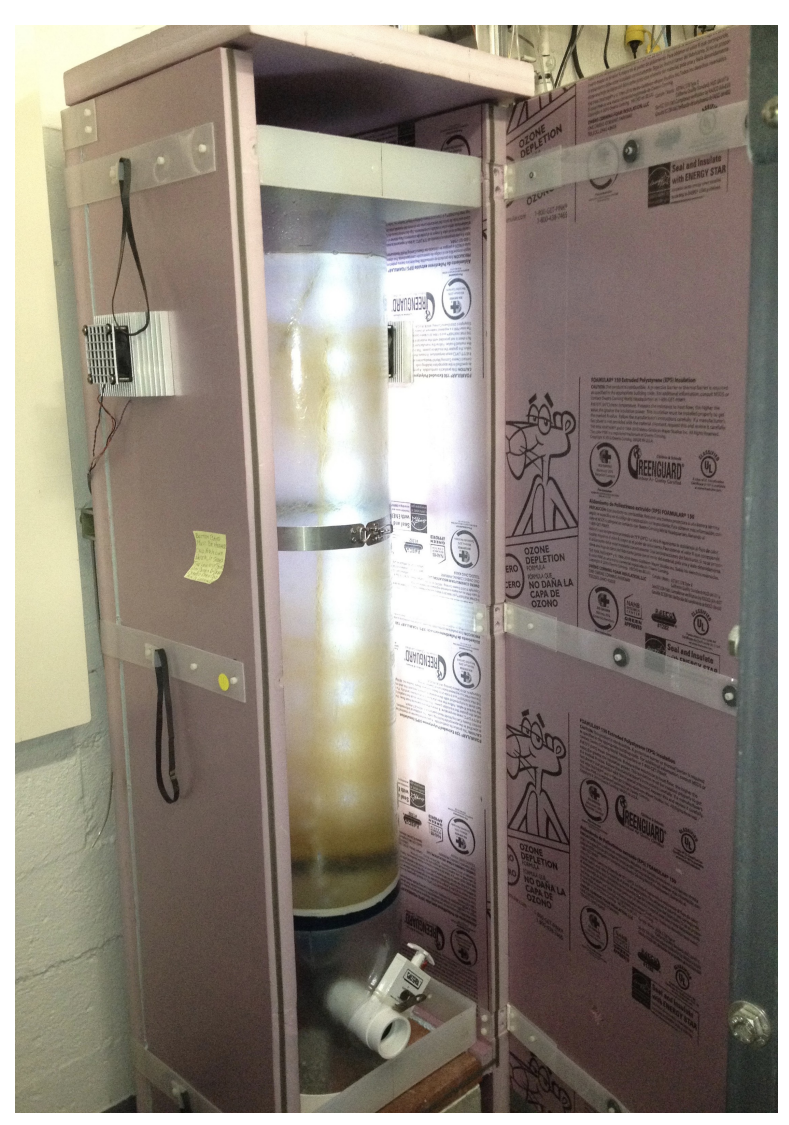

Fig. 3. An example medium scale larval culturing set-up. Larvae and food are kept in suspension in this 75-liter cylindrical tank by gentle aeration. For water changes, the valve at the bottom drains the tank; larvae are retained on a Nitex mesh by a forward filtration method similar to that pictured in Fig. 2 but at a larger scale. To maintain the larvae below ambient temperatures in this set-up, the tank is kept within a temperature controlled, insulated cabinet. Photo by C. Lowe. 


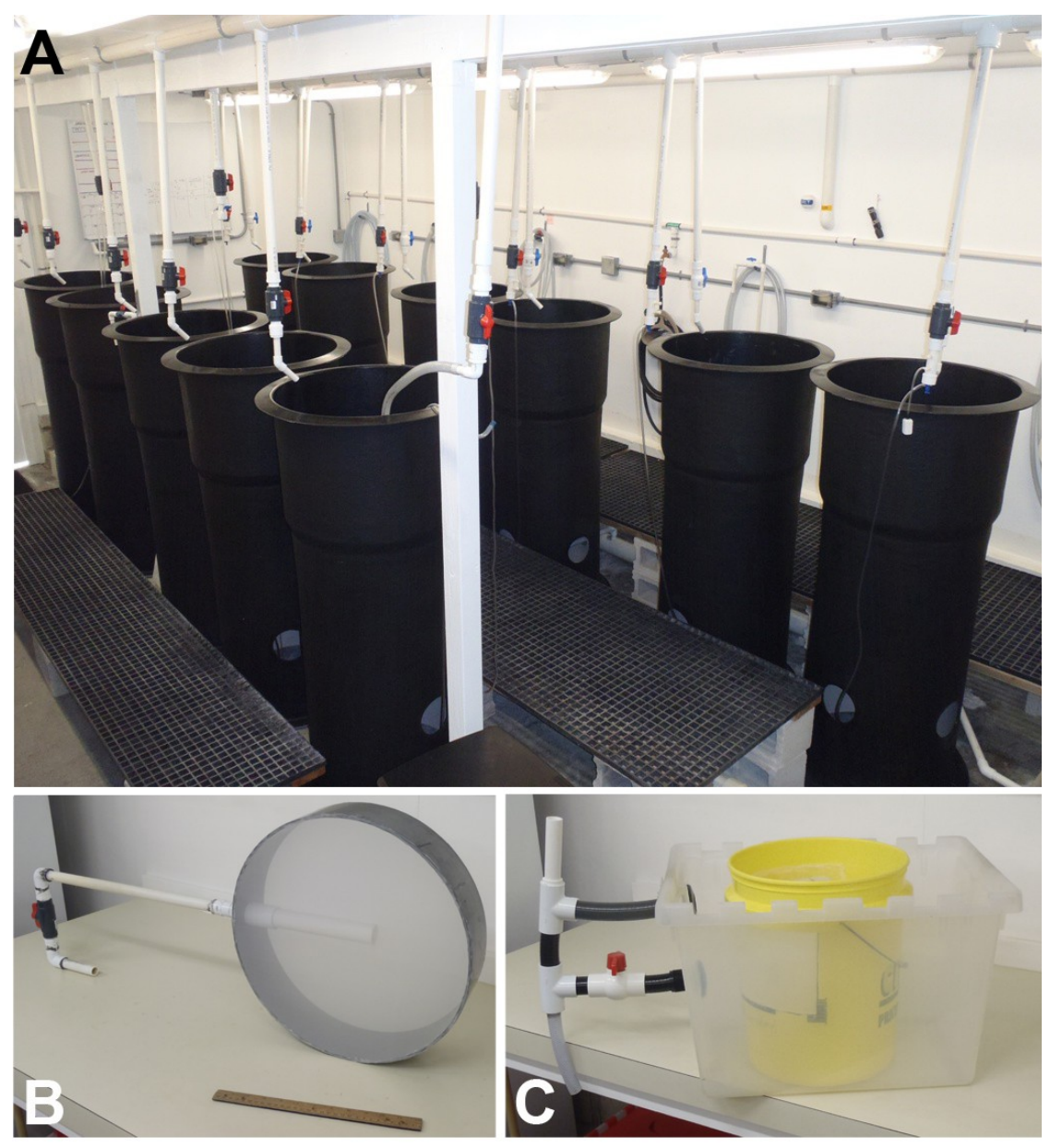

Fig. 4. An example large scale culturing set up. A) Interior of climate controlled larval rearing room. The black cylinders are 200-L cone bottom larval rearing tanks where larvae and phytoplankton are suspended with gentle aeration. B) Banjo screens are used for daily water exchanges by reverse filtration; this is a larger version of the reverse filtration apparatus shown in Fig 1 A. B) When larvae need to be moved, or if the tanks are in need of thorough cleaning, forward filtration is carried out using a screened bucket and tote system as described in the legend to Fig. 3. The principle is the same as the set-up shown in Fig. 2, but at a larger scale. Photos by D.L. Cohen. 


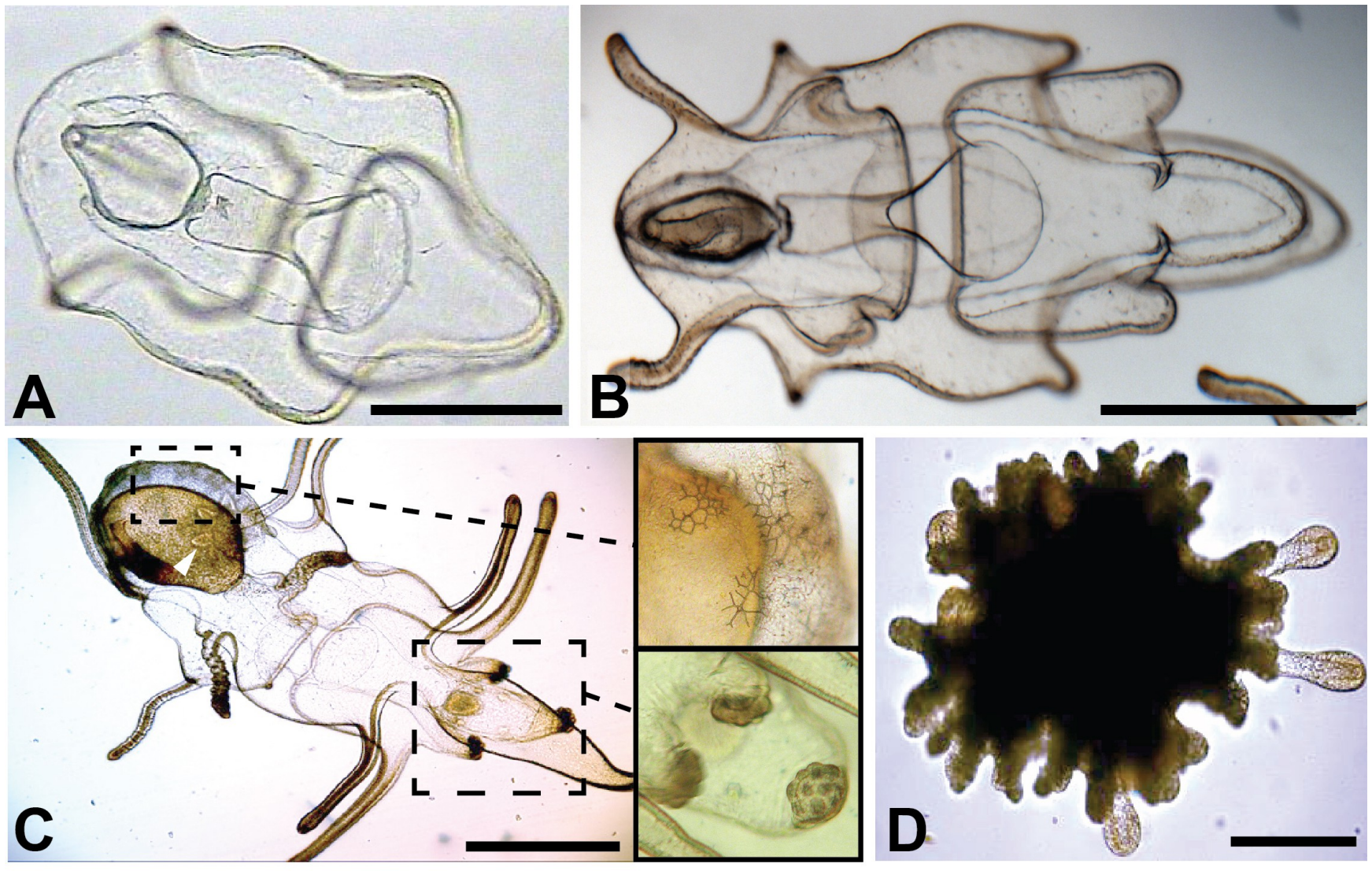

Fig. 5. Asteroid planktotrophic larval development through metamorphosis, as exemplified by the NE Pacific ochre sea star Pisaster ochraceus Brandt at approximately $14^{\circ} \mathrm{C}$. A) Early bipinnaria stage larva. B) Early brachiolaria stage larva. C) Advanced brachiolaria. Note the juvenile rudiment with 5-fold symmetry apparent (white arrowhead), as well as closeups of the juvenile skeleton (upper inset) and brachiolar arms (lower inset). N.b., the inset photos are from different larvae than

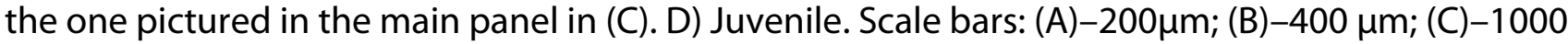
$\mu \mathrm{m} ;$ (D) $-300 \mu \mathrm{m}$. Main panel photos by S. George; inset photos in (C) by J. Hodin. 

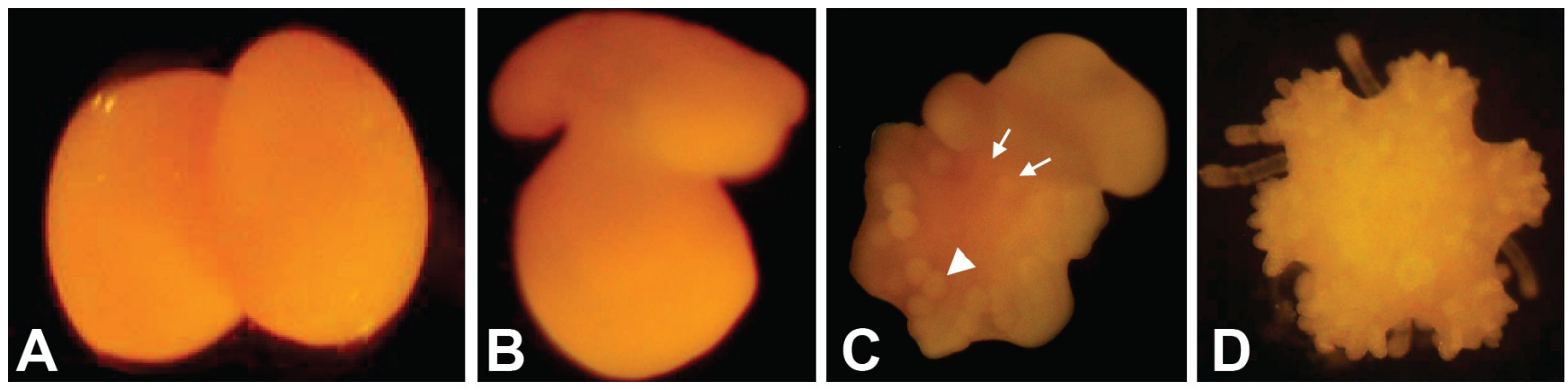

Fig. 6. Asteroid benthic larval development through metamorphosis in the six-armed brooding sea star Leptasterias hexactis Stimpson, from the NE Pacific. Dissected oocytes will mature by 1methyladenine using standard methods (See Chapter 1 in this volume), and in this way, embryos can be cultured in vitro apart from the mother through the juvenile stage (see Hodin 2006). A) 2-cell stage. B) Modified non-feeding brachiolaria larva. C) Brachiolaria larva undergoing metamorphosis, oral view, with podia forming (arrowhead) along each ambulacrum (arm) in the juvenile portion of the larva (lower left). At this stage, the primordia of 5 of the 6 juvenile arms are well-formed-with 3 pairs of podia each. The primordium of the 6 th arm is the last to form, here with only one pair of podia just visible (white arrows). D) Aboral view of 6-armed juvenile, with spines and tube feet

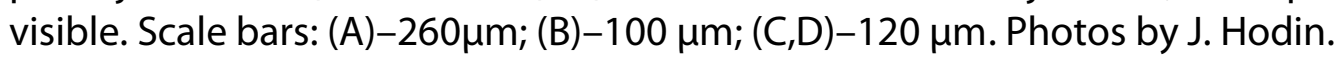




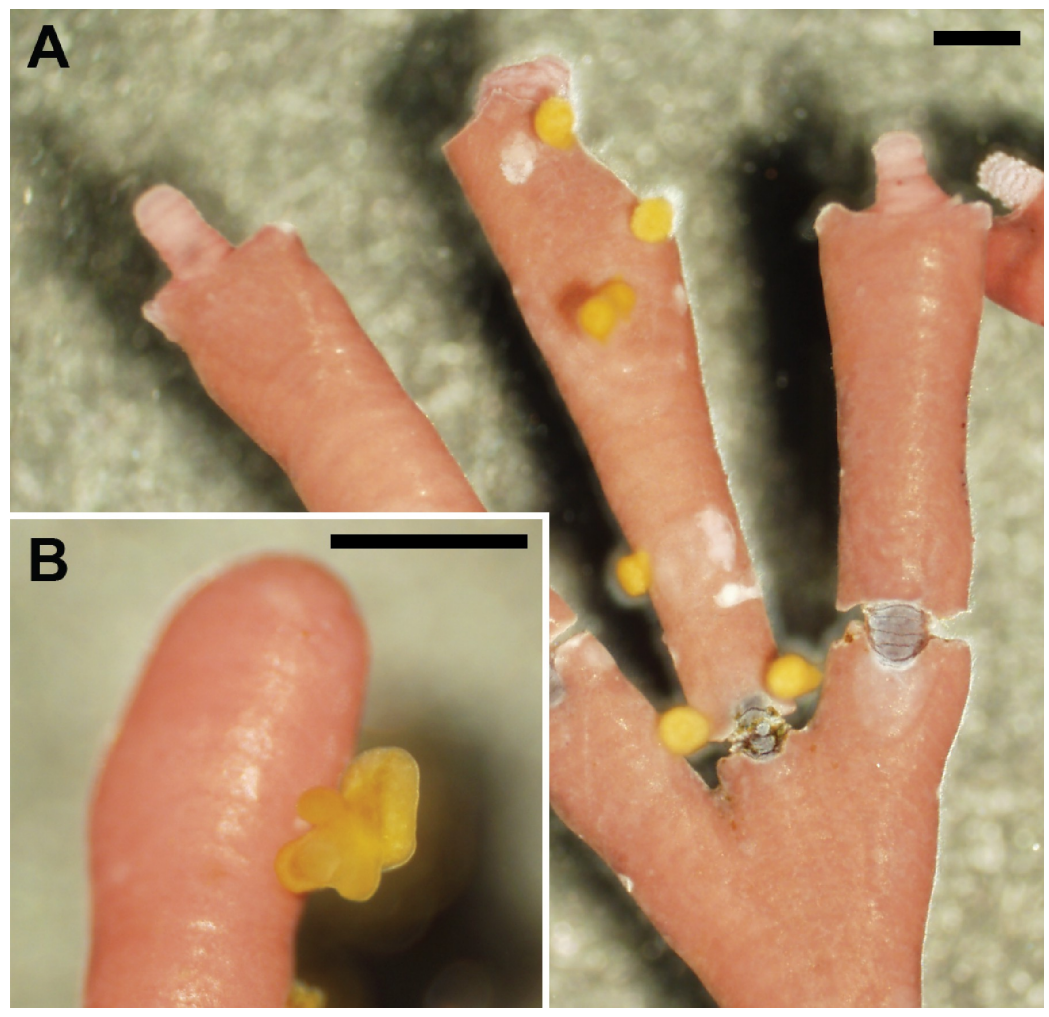

Fig. 7. Asteroid settlement on coralline algae (Amphiroa sp.), in the six armed cushion star Meridiastra gunnii Gray, from subtropical and temperate Australian waters. (A) Several settled $M$. gunnii larvae and juveniles (orange) on an Amphiroa frond. (B) Close-up of a single settled M. gunnii larva. Scale bars: approx. $1 \mathrm{~mm}$. Photos by M. Byrne. 


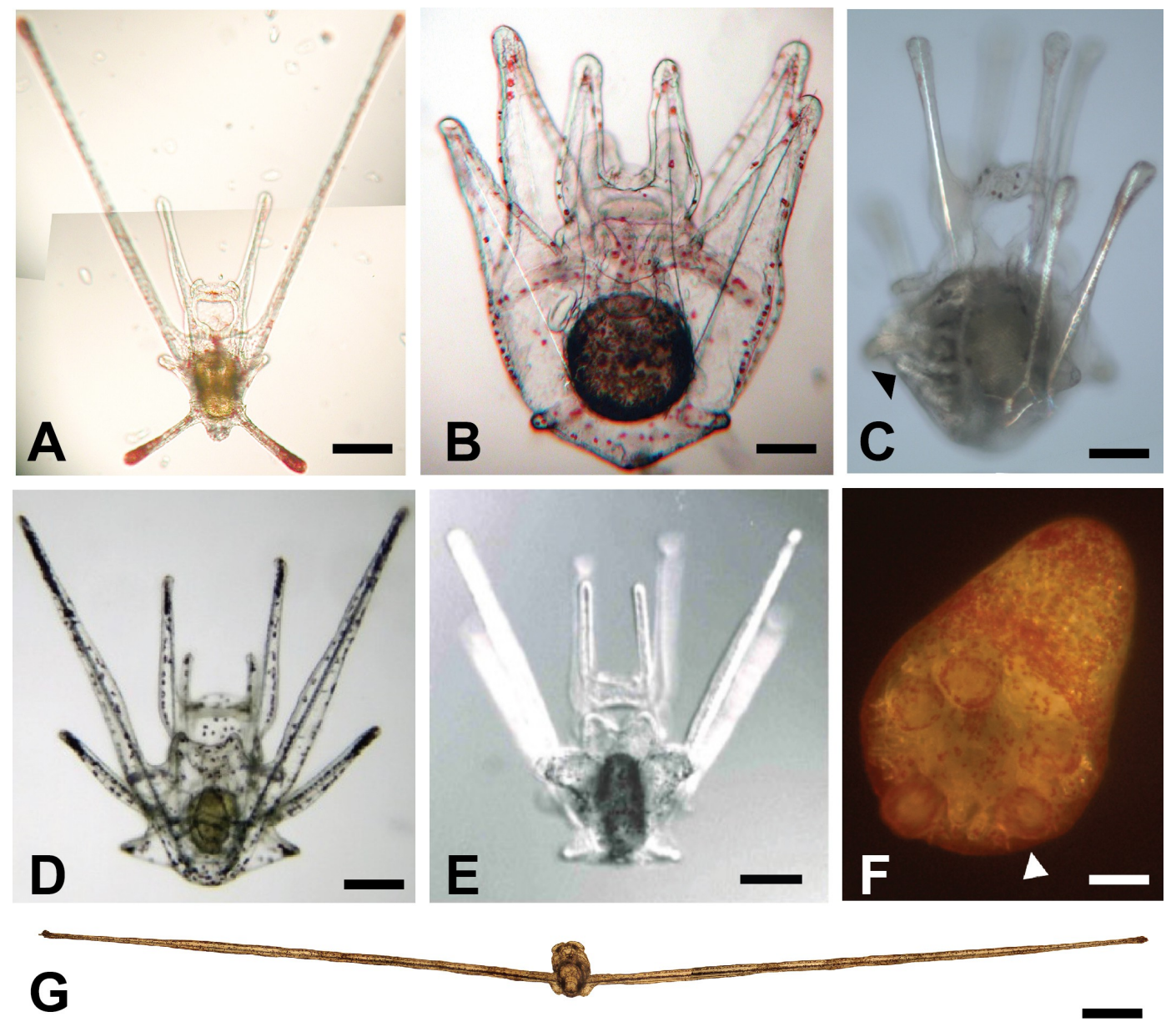

Fig. 8. Larval diversity in echinoids. A) 10-arm feeding pluteus of the NW Atlantic purple-spined sea urchin Arbacia punctulata Lamarck (Arbaciidae), pieced together from two photographs. B) 8arm feeding pluteus of the NE Pacific purple sea urchin, Strongylocentrotus purpuratus Stimpson (Strongylocentrotidae). C) Advanced 8-arm pluteus of the NE Pacific sand dollar, Dendraster excentricus Eschscholtz (Clypeasteridae). Well-developed adult spines (arrowhead) and other juvenile structures are visible in the large rudiment of this competent larva. D) 8-arm feeding pluteus of the tropical E Pacific urchin Echinometra vanbrunti Aggasiz (Echinometridae). E,F) Larvae from two sister species of Australian urchins from the genus Heliocidaris (Echinometridae) with radically different developmental modes. E) 8-arm feeding pluteus of $H$. tuberculata Lamarck. F) Non-feeding (lecithotrophic) larva of $H$. erythrogramma Valenciennes; juvenile rudiment clearly visible (one of the five primary podia indicated with white arrowhead). G) Feeding pluteus larva, resulting from a hybrid cross between two Indian Ocean long-spined urchins (Diadematidae): Diadema savignyi Audouin (male) and Diadema setosum Leske (female). Effectively, this advanced larva has only one pair of enormous arms remaining; the three other arm pairs formed transiently

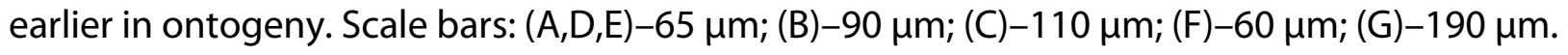
Photos by J. Hodin (A-C), J. McAlister (D), R. Emlet (E), P. Cisternas (F) and S. Dautov (G). E reproduced by permission from Byrne et al. (2001). 

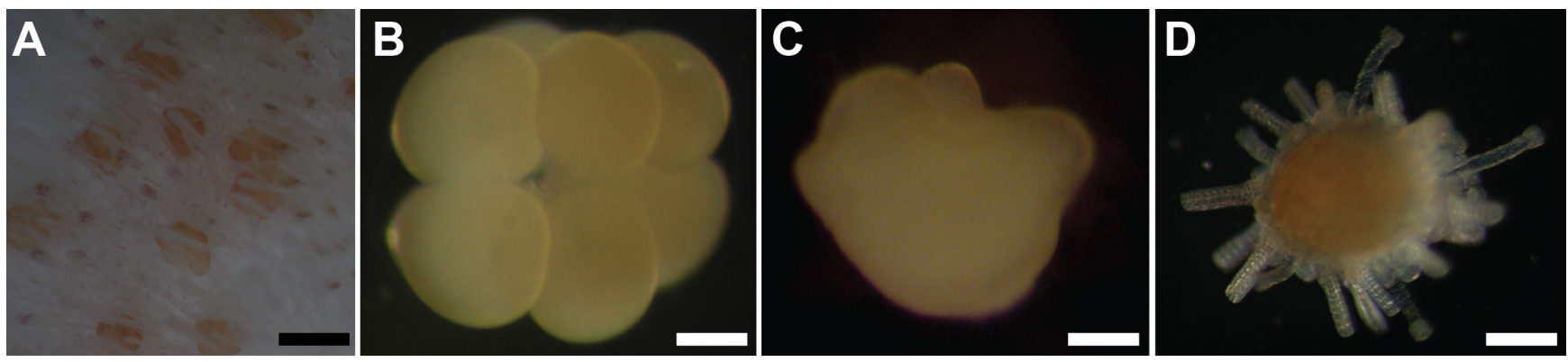

Fig. 9. Echinoid benthic larval development through metamorphosis in the brooding lamp urchin, Cassidulis caribaearum Lamarck (Cassidulidae), from the Eastern Caribbean. A) Larval brood among the oral spines of the mother. B) 8-cell stage. C) Non-feeding reduced pluteus larva (at approximately the same stage as the brooded larvae in A). D) Post metamorphic juvenile, at which point the offspring crawl away from the mother. Scale bars: (A)-500 $\mu \mathrm{m}$; (B)- $70 \mu \mathrm{m}$; (C) $-120 \mu \mathrm{m}$; (D)$200 \mu \mathrm{m}$. Photos by J. Hodin. 

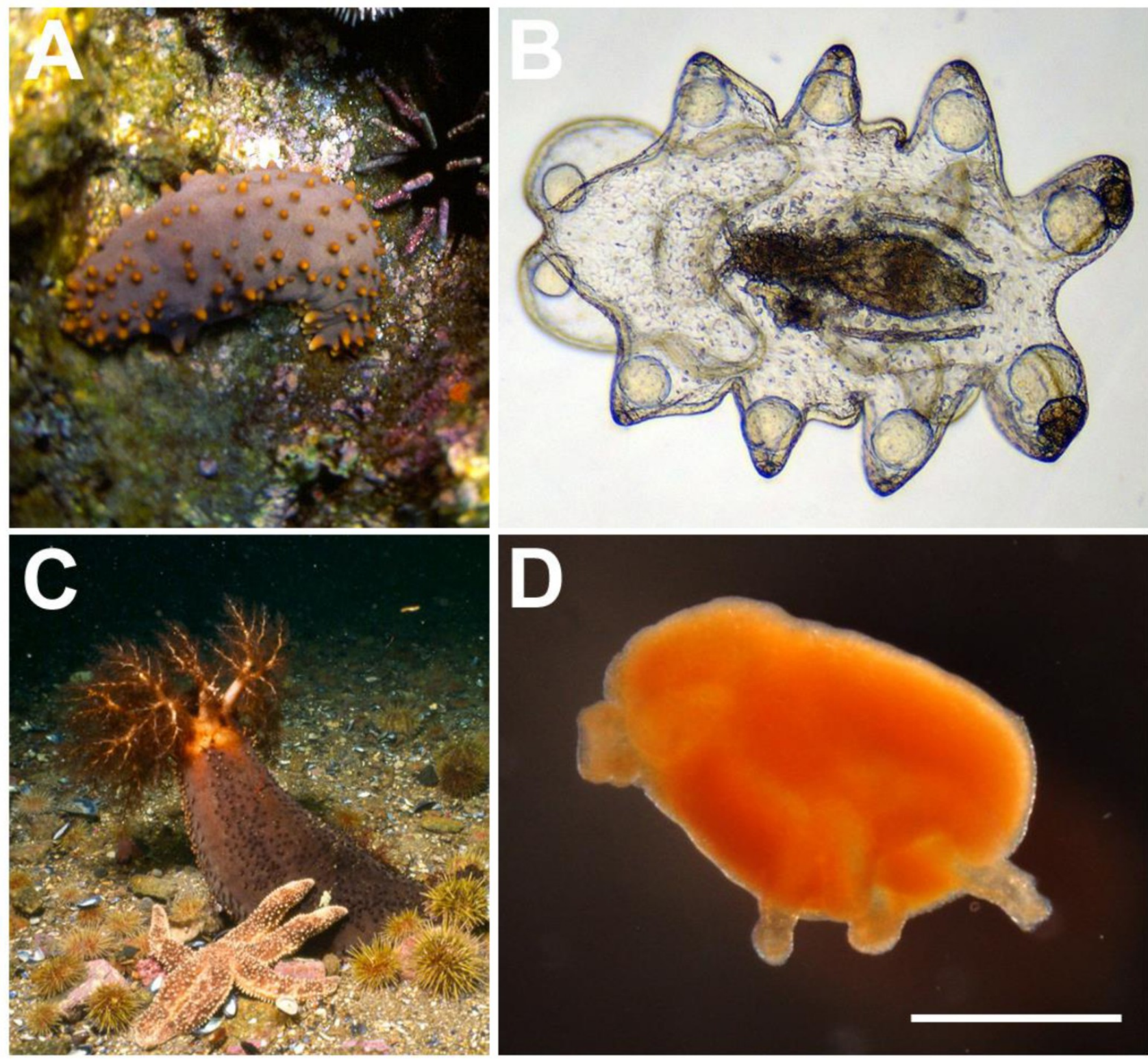

Fig. 10. Holothuroid adults and larvae of two commonly-cultured species. A) Adult of the brown sea cucumber, Isostichopus fuscus Ludwig, an endangered species from the Tropical Pacific and Latin America. B) Auricularia larva of I. fuscus. C) Adult of the orange-footed sea cucumber, Cucumaria frondosa Gunnerus, from the North Atlantic. D) Pentactula larva of $C$. frondosa. Scale bars:

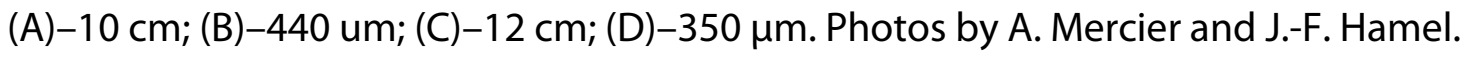




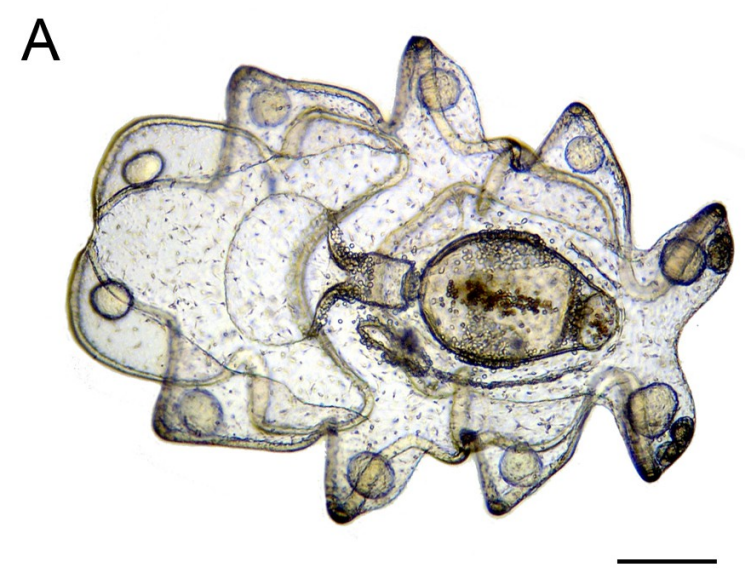

B

C

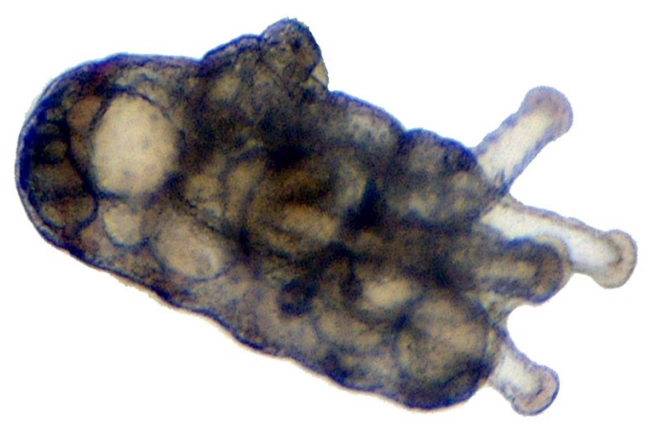

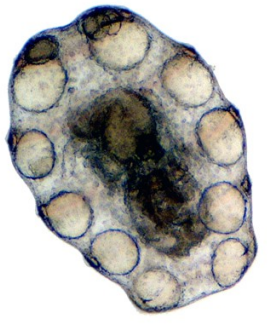

$\mathrm{D}$

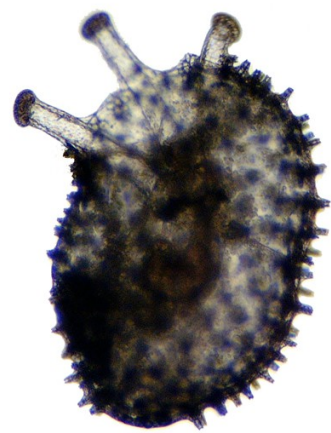

Fig. 11. Holothuroid planktotrophic larval development through metamorphosis in I. fuscus. A) Fully developed auricularia larva. B) Doliolaria larva. C) Pentactula undergoing settlement. D) Newly settled juvenile. Scale bars: $200 \mu \mathrm{m}$. Photos by A. Mercier and J.-F. Hamel. 


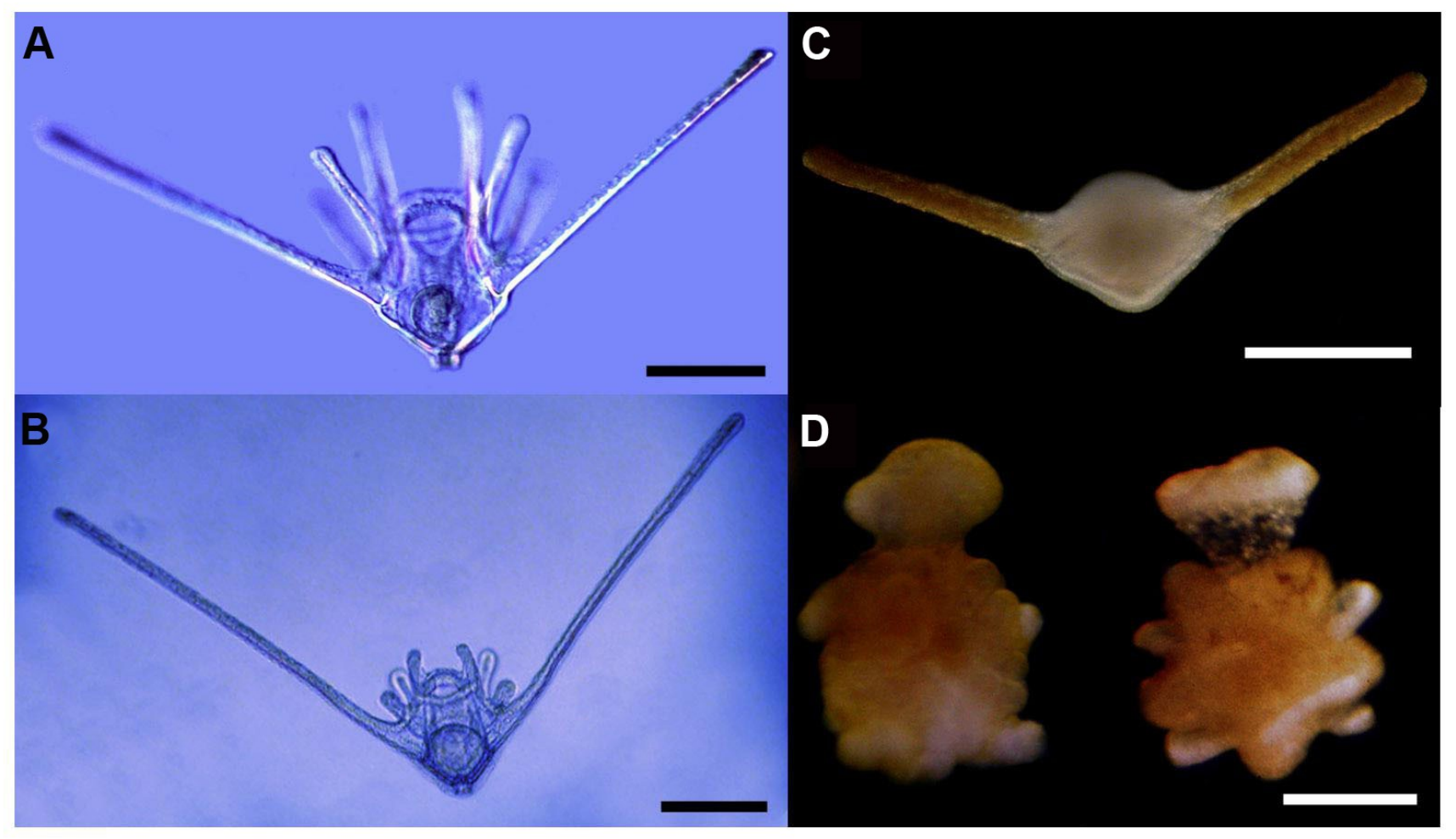

Fig. 12. Main larval types in ophiuroids. Fully developed planktotrophic ophioplutei of A) Ophiactis resiliens Lyman from Oceania and B) the spiny brittle star Ophiothrix spiculata Le Conte from the Eastern Pacific. C) Lecithotrophic ophiopluteus of Macrophiothrix caenosa Hoggett from Western Australia. D) Vitellaria larva of Clarkcoma canaliculata Lütken from Oceania. Scale bars: $100 \mu \mathrm{m}$. Photos by P. Cisternas (A, B, D) and J.D. Allen (C). 


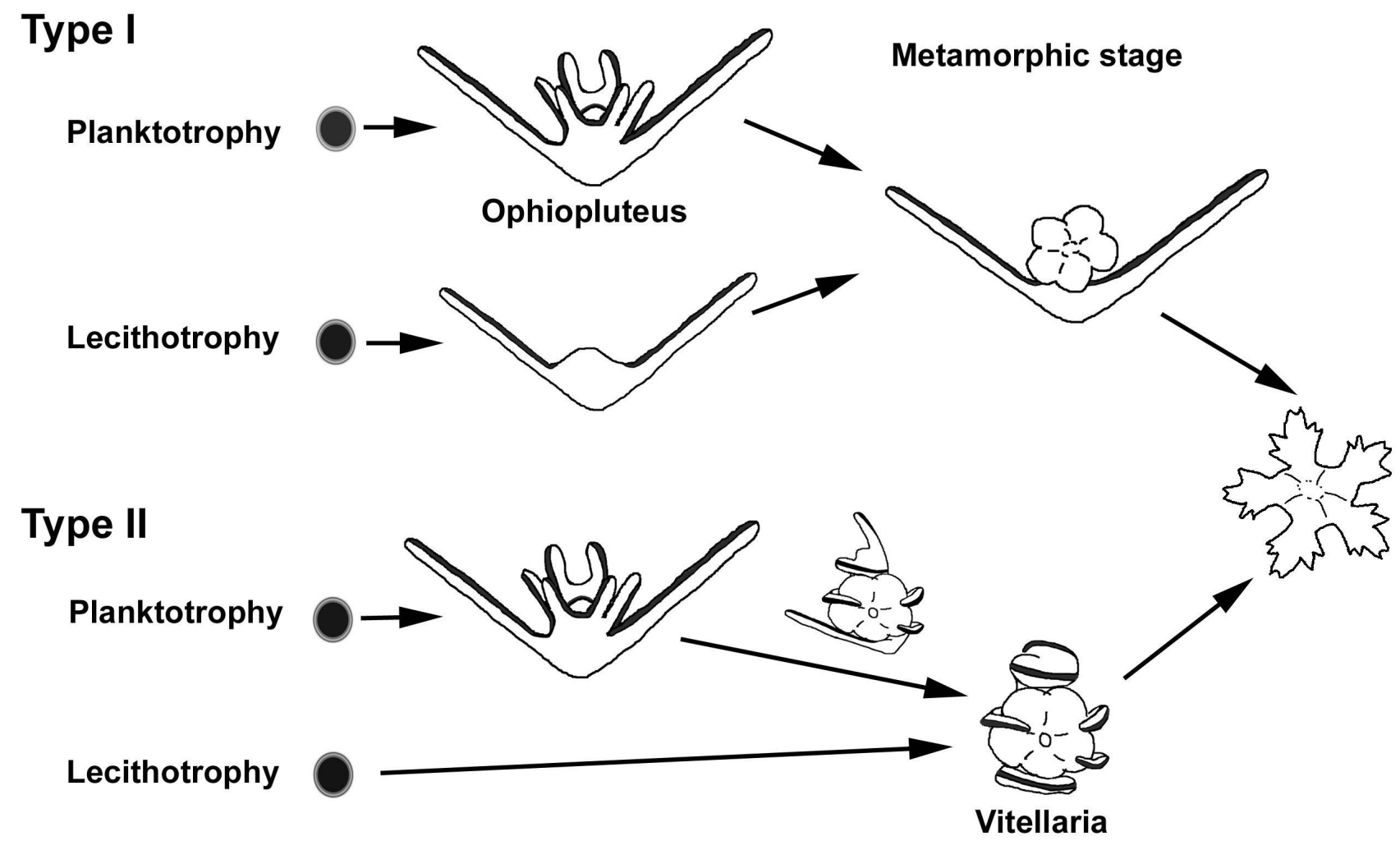

Fig. 13. Developmental patterns of ophiuroids with larval development (Type I and Type II) classified according to mode of larval feeding (planktotrophy versus lecithotrophy) and larval form during metamorphosis. 

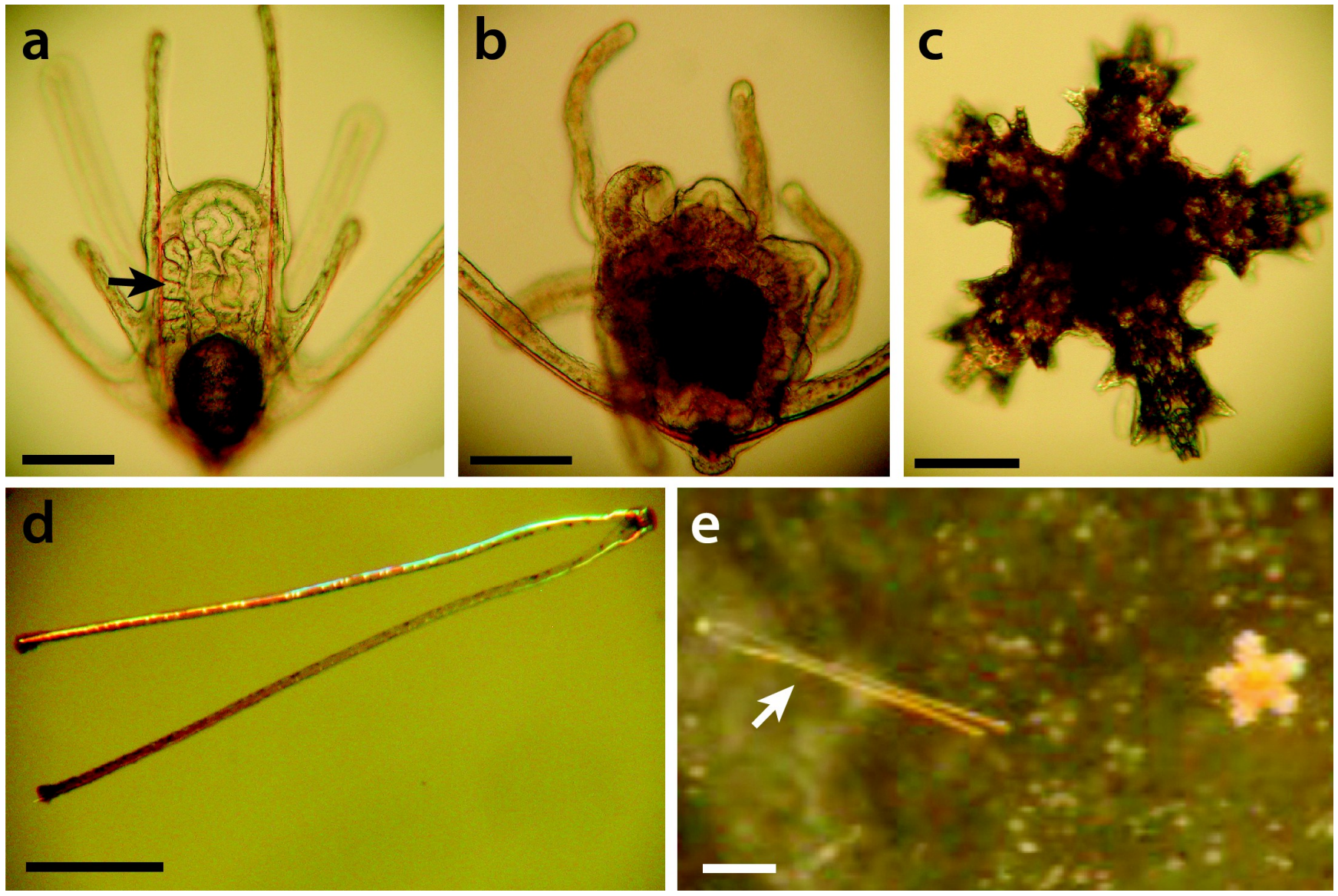

Fig. 14. Ophiuroid planktotrophic development though metamorphosis and post-settlement cloning in the daisy brittle star, Ophiopholis aculeata Lyman, a species with circumpolar distribution in the North. A) Initiation of 5 -fold symmetry in the rudiment; at this stage, the primordia of the 5 arms (one indicated with arrow) are visible on the left side. B) Disintegration of the larval arms as the larva nears the settlement stage. C) Settled juvenile. D) Cloning via discarded pair of posterolateral arms. E) Still image from a video showing discarded posterolateral arms swimming away from a justsettled juvenile. Scale bars: $100 \mu \mathrm{m}$. Photos by J. Hodin. 


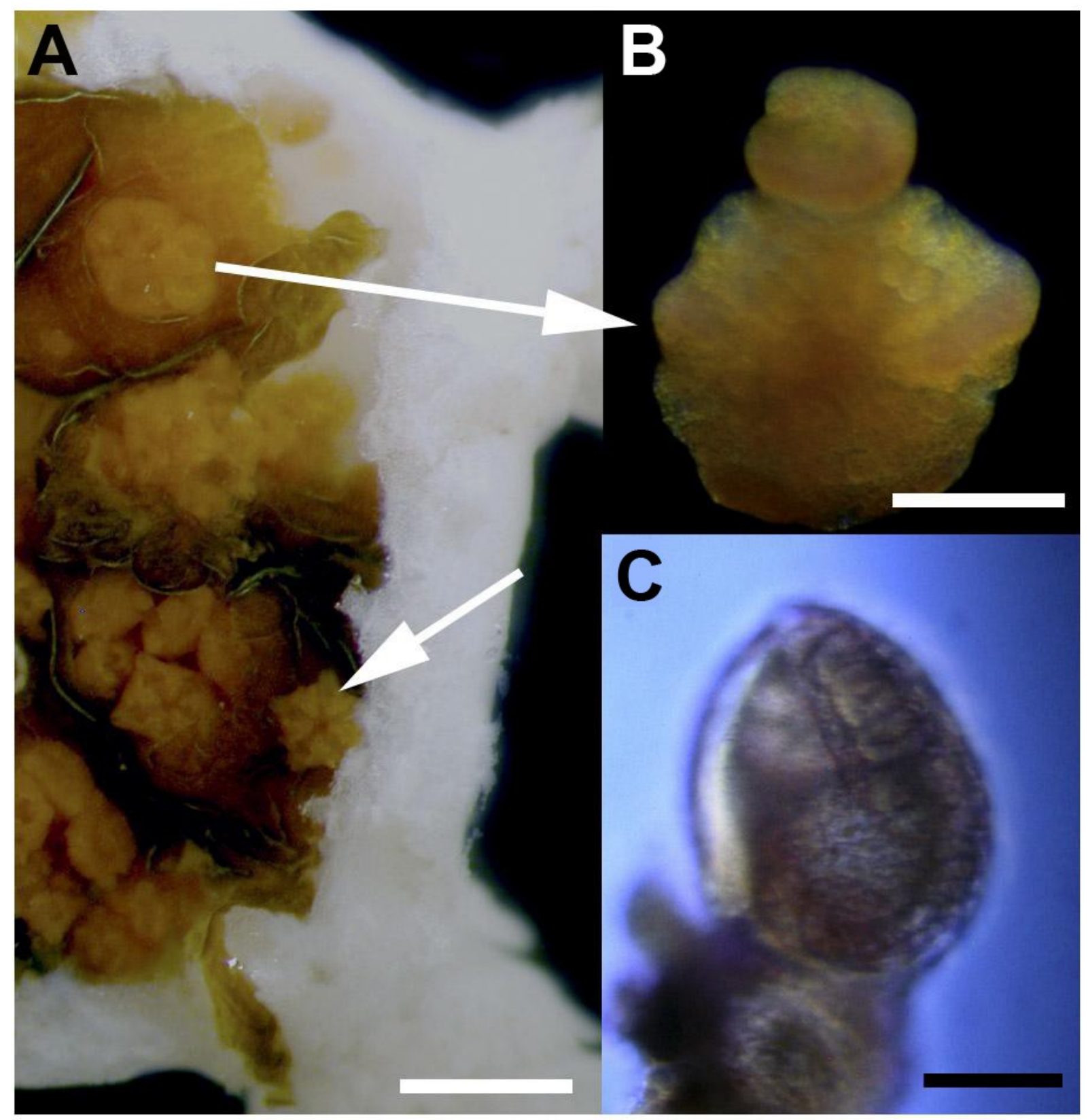

Fig. 15. Brooding ophiuroids. $A, B)$ Ophiopeza spinosa Ljungman. A) The disc and some of the digestive system has been removed to show developing offspring inside the bursae (arrows). B) Vitellaria larval stage from brood clutch in O. spinosa. C) Developing embryo of Amphipholis squamata Delle Chiaje partially attached to the bursal wall. Scale bars: (A)-600 $\mu \mathrm{m} ;(B)-300 \mu \mathrm{m} ;(C)-$ $100 \mu \mathrm{m}$. Photos by M. Byrne (A, B) and P. Cisternas (C). B reproduced by permission from Byrne et al. (2008). 